\title{
PROBLEMAS DE LA DETERMINACIÓN DEL TÓPICO TEXTUAL. EL SONETO EN EL SIGLO DE ORO
}

\author{
Antonio García Berrio \\ Universidad Autónoma de Madrid
}

O. El problema lingüístico-teórico fundamental que subyace al conjunto de mis investigaciones tipológico-textuales sobre organización macrocomponencial en sonetos españoles de los siglos XVI y XVIl es sin duda el de la determinación/ jerarquización temática. En la Lingüística general reciente, tanto sentencial como textual, se ha desarrollado, paralelamente a mis propios trabajos, un creciente interés por esta cuestión, en la que se deslindan varias líneas: desde la checa, que procede del interés por la "perspectiva funcional de la frase» (F. Daneš, 1970; 1975), con antecedentes muy concretos en los trabajos de Jan Firbas, a distintas aproximaciones como la de Östen Dahl (1974), donde ya se iniciaba un despegue del problema temático, no sólo respecto del interés estricto por el aspecto global de la uprogresión del discurson tema-comentario (Petöfi, 1975; Daneš, 1976: 34-36; HallidayHassan 1976: 325), sino también apuntando ya tempranamente al nuevo ámbito textual, donde resultaba obligado centrar previamente el problema, precisamente, en las cuestiones de determinación. Desde el ámbito de intereses generativistas la cuestión ha resultado también ro- 
zada, casi siempre en grupos de cultivadores no exactamente «ortodoxos» del método, tales como en trabajos de Sgall y colaboradores (1973), como en los de Longacre y los suyos (1970). Pero es precisamente en los trabajos de este último grupo (especialmente en 1976), donde yo situaría las más precisas zonas de proximidad. No se ha planteado hasta el presente Longacre tanto el problema de la determinación temática, como el de ofrecer criterios generales de tipologización textual, que indirectamente favorecen aquélla.

Junto a las aportaciones de Longacre habría que mencionar, cuando menos, por el volumen de los materiales indirectamente ofrecidos a la problemática central que nos ocupa, los estudios de M.A.K. Halliday (Halliday-Hasan, 1976). En los últimos años el interés por el tema ha cristalizado al menos en dos libros, de intereses muy próximos ya al del contenido de este trabajo, la miscelánea editada por Charles N. Li (1976) y el libro de Linda Kay Jones (1977); además de una importante aportación en el artículo de E. Agricola (1976). Dentro de 1980, en distintas aportaciones al simposio Nobel de Agosto sobre Textprocessing, se descubre un grado de sensibilidad muy notable a este tipo de cuestiones de la determinación temática, aun cuando no figurara ella, en sí misma, entre los tópicos explícitos del Simposio (1). Más recientemente aún apareció un artículo del húngaro Z. Bánréti (1982).

Aunque las menciones a los distintos trabajos que aquí he citado irán apareciendo en términos más concretos y circunstancias a lo largo de este artículo, conviene sin embargo adelantar desde el comienzo que ninguno de ellos ha constituido una estricta pauta para mis propias ideas y análisis, en el curso de mi investigación general o en el caso concreto de este trabajo, no ya para desarrollar una sugerencia precisa, sino ni siquiera para contradecirla. Se trata, como podrá ver claramente quien conozca aquellos trabajos y los míos, de cosas distintas que, publicadas casi todas al tiempo que avanzaba mi propia reflexión, no se han interferido. En realidad, la mención de todos los meritorios escritos que antecede obedece sólo a mi interés por demostrar que las mias son consideraciones que se mueven "también" en una determinada línea de intereses de la Lingüística actual, en la que la coincidencia con el objeto, determinación/jerarquización textual del tema, es más unívoca que los

(1) Por tratarse de trabajos conocidos como invitado al Simposio y en estado pre-print no me es lícito precisar o citar con más detalle las aportaciones concretas de los autores, donde se descubre tal tipo de intereses. En pruebas este trabajo han aparecido publicadas las Actas. 
puntos de partida empíricos y las vías metodológicas seguidas en el discurso. Singularmente mis intereses y métodos divergen más sensiblemente, por paradoja, de aquellos de los trabajos mencionados cuya inmediatez diriase más clara, a partir de los títulos, como el de L.K. 'Jones; creciendo por el contrario respecto de los estudios más estrictamente gramaticales de Halliday y Longacre.

O.1. La determinación del tema en un texto es, curiosamente, al mismo tiempo, un objeto científico de resolución muy difícil y una operación práctica continuamente ejercida de modo plenamente satisfactorio, consciente o inconscientemente, por la práctica totalidad de los usuarios de las lenguas (van Dijk, 1977; 1980; van Dijk - Kintsch 1978; van Dijk (ed.) 1980). Es experiencia vulgar la de sintetizar con brevedad, hasta en una sola frase, o incluso en una sola palabra - rótulo por lo general culturalmente convenido- el contenido de extensos fragmentos de discurso. Así una serie de breves titulares pretende comunicar económica y fielmente a los lectores el conjunto de los textos de un periódico, de la misma manera que los títulos de libros seleccionados cuidadosamente por sus autores aspiran a participar al lector, por procedimientos muy diferentes, el contenido de la obra del modo más exacto posible. El problema, pues, se plantea a mi juicio no tanto en términos de la posibilidad de la determinación del tema en el texto, que es una realidad indiscutible en la competencia lingüística; sino más bien de la exacta intersubjetividad de las formulaciones otorgadas al tema seleccionado, por una parte, y por otra de la mecánica lingüística de establecer y formalizar eventualmente, según las aspiraciones, un conjunto coherente de reglas de determinación, que haga explícito el sistema de mecanismos competenciales de selección, y establezca las necesarias condiciones de organicidad y jerarquización de las reglas que describan dicho sistema.

No ignoro las experiencias que establecen la dificultad para textos normales, tales como historias extensas, discursos filosóficos o técni$\cos$, de concretar intersubjetivamente un tema dado. A menudo, realizados ejercicios de sumarización, de selección temática (Halliday - Hasan, 1976: 27), o de titulación de un texto por un grupo de hablantes, incluso cultos y bien orientados en la tarea, se siguen resultados distintos en su apariencia. Con todo, aunque no sea como veremos éste nuestro caso, quisiera también destacar que se exagera evidentemente con este tipo de argumentos, en los que la intuición por los distintos hablantes de la representación significativa global del texto no es absolutamente discrepante, y regularmente no es contradictoria. Creo que, 
en este punto, las divergencias más visibles resultan imputables a detalles de formulación lingüística de dicha intuición de la representación. Al menos en términos relativos.

Sin embargo tales problemas resultan muy empequeñecidos en el caso del tipo especial de textos que yo me he propuesto. Los sonetos son textos o discursos literarios, es decir, altamente convencionalizados. En ellos la extensión del texto está de antemano fijada en catorce sintagmas versales de once sílabas de media, su organización macrosintáctica establece un conjunto de importantes reducciones, dentro de su combinatoria posible (García Berrio, 1980a). Por lo que se refiere a los temas, ya hemos establecido también reiteradamente el grado de drásticas restricciones impuestas por los convencionalismos de la tópica tradicional literaria (García Berrio, 1978-1979); pero sobre todo lo definitivo en este dominio es la buscada condición de unitematismo del texto, establecida conscientemente por la teoría y la práctica del género (García Berrio, 1975, 1976, 1980) precisamente como garantía de eficacia lingüístico-comunicativa y estética de esta clase de textos. El soneto bien constituido, pues, era por definición y práctica unitemático, su concepto, fórmula sintética temática, debía comparecer claramente al lector para que la composición ostentara su eficacia. En tales condiciones mi investigación sobre los sonetos clásicos ha partido deliberadamente de una clara posición de ventaja en este campo, con respecto a los estudios y ejercicios generales de determinación temática en otros tipos de textos, más extremos, libres, complejos y atópicos.

Con todo, creo que la referida ventaja es, vista de otro modo, una prudente salvedad metodológica. Si se proclama convincentemente las poderosas dificultades que revisten las operaciones lingüisticas de determinada jerarquización temática en los textos, parece prudente y razonable comenzar la tarea por aquellas modalidades textuales que, como la nuestra, ofrecen ventajas iniciales. Aun así los problemas, como se verá en este artículo, no son pocos. Estoy seguro de que las enseñanzas metodológicas derivadas de este ejercicio "a escala reducida», pueden ser extrapolables con fruto a otros textos de complejidad mayor.

1.0. Para ilustrar la condición unitemática del soneto bien construido, y ejemplificar operaciones de localización textual del tema, séame consentido centrarme, para comenzar, en un grupo reducido de sonetos de Góngora. El gran poeta cordobés es, a mi juicio, uno de los más perfectos constructores de sonetos amorosos de nuestro Siglo de Oro, y quizás sea la mejor prueba de ello la inequivocidad con la que sus textos 
evidencian y descubren su entramado constructivo en torno al tema central. Comenzando por los sonetos más juveniles, más próximos, por tanto, al esquema manierista de un Fernando de Herrera, la linealidad del enunciado temático constituye sin duda su característica más sobresaliente. Veamos, por ejemplo, uno de los más tempranos, compuesto en 1582.

\author{
I) \\ Tras la bermeja Aurora el Sol dorado \\ por las puertas salía del Oriente, \\ ella de flores la rosada frente, \\ él de encendidos rayos coronado.
}

Sembraban su contento o su cuidado, cuál con voz dulce, cuál con voz doliente, las tiernas aves con la luz presente en el fresco aire $y$ en el verde prado,

cuando salió bastante a dar Leonora cuerpo a los vientos y a las piedras alma, cantando de su rico albergue, y luego

ni oi las aves más, ni vi la Aurora; porque al salir, o todo quedó en calma, o yo (que es lo más cierto), sordo y ciego.

La salida de la dama y sus efectos en el paisaje (versos 9-11), tema arquetípico desde la tradición italiana, establece un claro punto central en el eje temático-narrativo, que incluso subrayan elocuentemente partículas temporales: tras (verso 11// cuando (verso 9)/ luego (verso 11). Quedan, pues, distribuidas las series narradas secundarias en torno a un eje que ocupa la que podemos señalar como central con toda propiedad y desde cualquier punto de vista.

Conviene no olvidar que la intención de nuestra búsqueda temática es claramente selectiva y jerárquica, con lo que ha de distinguirse de la puramente acumulativa, que es la practicada en la tradición del formalismo ruso desde Tomaševskij (Todorov, 1968; García Berrio, 1973), o de la folklorística y de "texturas» en el entendimiento de $E$. Frenzel. En tal sentido, en el texto propuesto el posible tema amanecer, por ejemplo, no encierra otro interés para nuestro propósito que el dar entrada a una situación' procesual, dentro de la que se ordena y jerarquiza a un mo- 
mento central, la aparición de la dama, que seleccionamos como tema central, o simplemente tema del texto.

En Góngora abundan los textos organizados según esta estructura lineal-progresiva, absolutamente aproblemática desde el punto de vista de la selección/jerarquización temática; especialmente en el período juvenil. Así, en otro soneto del mismo año 1582, descriptivo-ponderativo, "Al tramontar del sol, la ninfa mía", el establecimiento de un punto central temático resulta aproblemático, no sólo por la linealidad sin fracturas de la sucesión temático-progresiva del enunciado, sino hasta por el mismo subrayado explícito de marcas gramaticales que la organiza y refuerza. De tal suerte, se opera la construcción del marco o decorado en los cuartetos, mediante fórmulas temporales (A/ tramontar) más formas verbales en pasado continuo (crecer hacia/ondeábale); frente al centro temático del primer terceto (fórmula temporal, más luego que/formas verbales en pasado puntual, ciño); añadiéndose la coda desglosada del último terceto, con un cambio de perspectiva personal (el/ella/yo) y de tiempo verbal en futuro (juraré), pasado puntual (/ució) y presente habitual (ilustra).

Más raramente en estos sonetos juveniles de Góngora, cortados sobre estructuras temático-organizativas marcadamente renacentistas, la selección de un punto central en el eje sucesivo ha de observar distorsiones entre enunciación y enunciado; sin alterar de todos modos la situación estrófica estructural central - siempre en el primer terceto - del tema básico. Ejemplo posible sería el del soneto, también fechado por los editores en 1582, "Raya, dorado Sol, orna y colora».

II)

Raya, dorado Sol, orna y colora del alto monte la lozana cumbre; sigue con agradable mansedumbre el rojo paso de la blanca Aurora;

suelta las riendas a Favonio y Flora, y usando, al esparcir tu nueva lumbre, tu generoso oficio y real costumbre, el mar argenta, las campañas dora,

para que desta vega el campo raso borde saliendo Flérida de flores; mas si no hubiere de salir acaso, 
ni ef monte rayes, ornes, ni colores, ni sigas de la Aurora el rojo paso, ni el mar argentes, ni los campos dores.

Obsérvese que en este texto la selección del tema central de la salida, de la dama, queda decidida en competencia con toda una serie de posibles criterios de indole superficial que lo descartarían como tema central, a cuya problemática nos referiremos por extenso en otros parágrafos de este mismo artículo. He llamado superficiales a tales criterios, no para destacar apriorísticamente condición alguna de subsidiaridad en los mismos, sino para definir el ámbito lingüístico en el que operaría su supuesta principalidad. En efecto, es en la estructura lineal terminal del soneto, equivalente textual (Petöfi, 1973) del límite terminal de la estructura de superficie sentencial en los términos habituales de las gramáticas transformativo-generativas, donde entran en competencia otros temas, en virtud de determinados criterios de superficie, con el que he seleccionado como central. Entre los criterios de superficie aquí atendibles, suele operar, en casos como el actual, como el más problemático el de la extensión textual de la manifestación superficial del tema. Asi en nuestro ejemplo las operaciones encomendadas por nuestro poeta al Sol, constitutivas de tema secundario, se extienden a los dos cuartetos en su aspecto positivo, y al segundo terceto en el negativo, frente a la extensión del desarrollo superficial del tema, reducido escasamente a los tres versos del primer cuarteto. El anterior presupone dos criterios, tales como en este caso la subsidiaridad en la estructura profunda de actantes dominantes en la organización de la estructura de superficie. El Sol, por ejemplo, es actante cuya actividad precede y domina (prepara la salida de la dama) a la de la propia dama en la organización textual en que se organiza superficialmente el texto, creada básicamente por el punto de vista del sujeto de la enunciación, el poeta; sin embargo resulta obvio que en la estructura profunda la dominancia sobre el Sol la crea la dama, la condición facultativa de cuya salida determina el sentido de las órdenes del poeta y, por consiguiente en la lógica especial de la ficción poética, las operaciones del sol.

Un caso todavía más extremo para ilustrar este mismo tipo de conflictos puede ofrecerlo el soneto de Fernando de Herrera que comienza "Aquí, do me persiguen mis cuidados» (2). Como puede verse, se trata de uno de esos textos de muy difícil decisión en punto a establecer la prioridad temática. De un lado se registra el tema desarrollado en las tres primeras estrofas, que podriamos catalogar de lamento o sufrimiento desesperado $\left(4, c_{1}\right)$, con una serie de resonancias temáticas secundarias muy distintas, «escenario» $\left(4_{1} c_{4}\right)$ en el 
primer cuarteto, $y$ «esperanza-engaño/desesperanza-desengaño» en el primer terceto. Pero, de otro, el segundo cuarteto introduce un elemento temático decisivo, el confidente coadyuvante desengañado en situación de ayudar $y$ al que se solicita la ayuda $\left(4_{1} d_{2}\right)$; precisamente por este desarrollo de una funcionalidad propia que se reconoce en el confidente, alcanza éste la potencialidad de constituirse en tópico temático, a diferencia de cuando se trata de un puro vocativo para sustentar la apelación. Atendiendo sólo al criterio de mayor extensión en la superficie textual tendríamos que inclinarnos a otorgar condición de tópico temático al sufrimiento; sin embargo la reconstrucción de la historia lógica y generativa del texto prima -entre otros criterios que vienen a reforzar a éste - la decisión en favor del confidente. De la misma manera que resulta lógico que la construcción activa aparezca en la base de cualquier forma de pasiva, la expresión causal resulta más profunda que su posible transformación consecutiva; es sólo fruto de formalización «ad hoc» bastante superficial la alternativa formal consecutiva, fácilmente deducible como transformación desde su base en la construcción causal.

De este modo, en el ejemplo anterior, el sumario textual a): "Ayudadme vos, que estáis libre de amor, porque yo sufro", precede en la estructura textual profunda al sumario b), que establecería la construcción consecutiva, y con ella la opción de constante funcional temática a favor del sufrimiento: "Yo sufro, por consiguiente ayudadme vos que estáis libre de la carga de amorn. Obsérvese además que una serie de indicios y criterios adyacentes vienen a confirmar la decisión que he-

(2) Véase el texto de referencia:

Aqui, do me persiguen mis cuidados, solo, sin mi Luz bella, $i$ ofendido, en noche de dolor siempre ascondido laménto mis desseos engañados.

Buelvo a vêr mis contentos ya passados, para mayor afan; qu'el bien perdido mas duele al que se vê'n confuso olvido, i contra si sus males conjurados.

Cuanto inténto alentar mi acerba pena; $i$ cuanto fúndo en esperança $i$ tengo, todo gasta i destruye mi tormento.

Vos, que, rota d'Amor l'impia cadena, respirais d'el trabajo; que sostengo, dadm'esfuerço en tan grave sentimiento. 
mos tomado de desestimar el criterio de extensión textual en favor del de dominancia profunda. Piénsese sobre todo en el decisivo principio que denominaremos (1.2) regla textual constructiva o métrica, que descubre, para el tipo de composiciones más bien tardío-manieristas y barrocas (3) como ésta, la creciente tendencia a la implantación temática en final de texto, por razones de "ponderación conceptuosa»-o "suspense» comunicativo- que figuran en las reglas de base de la poética conceptista. $Y$ adviértase, a tal propósito, que en nuestra decisión no estamos ponderando simplemente sumandos de capricho apriorista; decimos, por el contrario, que la coincidencia de los dos criterios convergentes refuerza nuestra decisión en favor de la jerarquización predominante del tema del confidente, porque lo que la llamada regla métrica establece es pura y simplemente la constatación de un determinado hábito de construcción textual del soneto en los poetas de un período determinado, verificado sin dudas por nosotros, en infinitos casos menos problemáticos que el actual, que retrae el concepto o tema textual básico al último terceto de la composición (4). En otro lugar de este mismo estudio nos extenderemos en consideraciones más porme-

(3) Téngase presente la incidencia de observaciones como ésta en el importantísimo problema de la obra Versos, a la que pertenece el soneto que estamos comentando, entre Herrera y Pacheco, según la cuestión debatida, entre otros, fundamentalmente por el editor José Manuel Blecua, y el estudioso herrerino Oreste Macri. A éste, como a tantos otros importantes debates histórico-literarios, filológicos y de atribución de autores, tiene mucho que añadir el tipo de verificaciones macrocomponenciales, en que nos movemos nosotros. Téngase en cuenta que los argumentos de las distintas opiniones, en éste como en los demás problemas, se han establecido hasta ahora sobre la única base disponible del intuitivismo estilistico microcomponencial. Quedan por tanto una mitad de las razones, $y$ en mi opinión no las menos decisivas, por ser convocadas a examen. Al caso de las obras de Herrera esperamos dedicar en breve un extenso estudio desde esta perspectiva tipológico-macrotextual.

(4) El tema textual básico constituye el núcleo de la macroestructura textual, de la que, en un nivel menos profundo, forman parte los temas secundarios. La manifestación textual lineal es la parte terminal de la microestructura textual, la cual es, a su vez, resultado generativo de la macroestructura. Por tanto, en el texto la macroestructura subyace a la totalidad de la manifestación textual lineal, por lo que el tema textual básico subyace a la totalidad de dicha manifestación. Esto no es obstáculo para que en determinados textos concretos y tipos de textos una parte de la manifestación textual lineal quede especializada en la expresión del mencionado tema textual básico, que no subyace exclusivamente a ese fragmento de manifestación textual lineal. La relación que se establece entre la parte de la superficie del texto en la que se localiza el tema textual básico y este tema es doble: por un lado hay entre aquélla y éste una relación indirecta, al estar dicha parte integrada en la manifestación textual lineal el tema básico subyace al mencionado fragmento porque subyace a toda la manifestación textual; por otro lado, al explicitarse en dicho fragmento el tema básico, hay entre aquél y éste una relación especial, directa, resultado de unas determinadas reglas de generación textual que proyectan el tema textual básico de la macroestructura textual en un espacio concreto de la manifestación lineal terminal. 
norizadas sobre esta misma cuestión teórica de la precedencia de las razones de dominancia profunda sobre las de extensión superficial; singularmente se ciñe allí nuestro discurso al problema central de la precedencia causa-consecuencia, así como a otras cuestiones relevantes también en este mismo soneto y en nuestra decisión de jerarquización temática como la de la regla genérico-específico (García Berrio, 1981), o la cuestión del especial estatuto temático del confidente (García Berrio, 1980). Cuestiones todas cuyo contenido no contradice nuestra sanción temática de este soneto, pero cuyo desarrollo extenso desviaría el orden de trabajo, al alejarnos de la cuestión específica que nos ocupa.

1.1. En mis primeras exposiciones del apartado temático de la teoría tipológico-textual adelantaba ya, de manera aproximada e intuitiva, los criterios de urgencia para la determinación/jerarquización temática en el texto (García Berrio, 1977; 1978: 27-28). Hasta aquí he razonado y ejemplificado en el parágrafo anterior el que allí llamaba criterio de extensión en el nivel explícito textual, que se cumplia en el primero de los sonetos transcritos y no en el segundo, precisamente en función de los otros dos criterios simultáneos a que entonces me refería, a saber: el criterio de medularidad en el plano generativo-textual de la macroestructura, y el criterio de topicidad histórico literario. Al criterio de medularidad he aludido ya en mi razonamiento anterior, y aún he de tornar reiteradamente en lo sucesivo. Respecto al criterio de topicidad, resulta evidente que su acción no ha dejado de ser decisiva en las operaciones de determinación/jerarquización del tema en los dos ejemplos anteriores, para corroborar la decisión tomada sobre los otros dos en el ejemplo primero, y para reforzar la preponderancia otorgada al criterio de medularidad sobre el de extensión de la explicitud superficial en el segundo.

En efecto, la topicidad histórico-literaria afecta en estos ejemplos a dos órdenes lingüísticos, en el sentido de determinar un orden de expectativa y exclusión como sistema de presuposición previo a cada ejercicio concreto de análisis. $Y$ esto tanto en el plano temático, como en el de la disposición textual. Temáticamente nuestros conocimientos culturales sobre la historia literaria del siglo XVI nos previenen de la existencia de determinados subgéneros temáticos en la lírica $y$, consecuentemente, de la ausencia de otros. De esta manera, esperamos que un poema pueda ser amoroso, presuponiendo hasta intuitivamente la extensión del inventario de actantes y de sus funciones básicas, entre los que no cabe el sol, o las tormentas en términos de agente o de sujeto. Aunque en virtud de criterios lógicos no sea descartable por principio una poesia «natural», que pudiera tematizar centralmente la consideración del sol; 
nos consta sin embargo que en la lógica especial que regulaba el dominio cultural de la lírica románica de los siglos XIV al XVII, tales temas no encontraban cultivo. Es más, desde muchos siglos antes, sabemos que el «De rerum natura» de Lucrecio como la «Farsalia» de Lucano eran invocados tradicionalmente como temáticas límite de la poeticidad, aun en su condición de tratados versificados. He aquí, pues, un ejemplo de cómo un criterio de orden cultural, no inmediatamente lingüístico sino en el nivel de las presuposiciones, establece el arbitraje definitivo entre criterios lingüísticos, extensión superficial vs. medularidad generativa, en las operaciones de jerarquización/determinación temática.

Quizás un ejemplo todavía más decisivo en una situación muy análoga a la anterior puede ofrecerlo el conocido texto de Góngora que comienza "Cosas, Celalba mía, he visto extrañas»

Cosas, Celalba mía, he visto extrañas: cascarse nubes, desbocarse vientos, altas torres besar sus fundamentos, y vomitar la tierra sus entrañas;

duras puentes romper, cual tiernas cañas; arroyos prodigiosos, ríos violentos, mal vadeados de los pensamientos, y enfrenados peor de las montañas;

los días de Noé, gentes subidas en los más altos pinos levantados, en las robustas hayas más crecidas.

Pastores, perros, chozas y ganados sobre las aguas vi, sin forma y vidas, y nada temí más que mis cuidados.

Para cualquier lector de este texto sin una muy especial competencia en la lengua española del siglo XVI, la selección del tema del sufrimiento amoroso, resulta casi imposible. Si nos atenemos a la extensión de lo dicho, sin poder rechazar a primera vista como en el caso anterior un criterio en competencia de orden de medularidad generativo-textual, tendriamos que concluir que estamos en presencia de un soneto especial - raro o excepcional ateniéndonos a la presuposición históricoliteraria antes comentada de ausencia de temas «naturales» en el cultivo poético de la época - un soneto "natural» o incluso "meteorológico», consistente en la descripción de unas lluvias catastróficas. Sin embargo es otra presuposición cultural diferente, la que reinstaura este texto en 
el dominio normal de la regla; y no debe olvidarse que una de las características que nuestros estudios van descubriendo más sólidamente implantadas en el sistema tópico de la cultura clásica, es sin duda la sistematicidad sin excepciones de su construcción. El valor de «especialización» del lexema cuidados (verso 14), verdadero tecnicismo central en el lenguaje de la lírica amorosa del siglo XVI, despeja toda duda, reestableciendo una imagen generativa del texto que lo confirma incuestionablemente como texto amoroso. "Cuidado", significando en español actual estándar «solicitud y atención para hacer bien una cosa», "dependencia o negocio que está a cargo de uno» y urecelo, sobresalto o temor" - aparte de una larga serie de otros matices conexos con los anteriores en modismos o frases hechas- (Diccionario Academia, 1970), combinaba los tres sentidos básicos de su significación general, implicándolos en relación de causa-consecuencia, para determinar el valor de usufrimiento y desvelo del amante en la relación amorosa, que tenía en el Siglo de Oro. Todavía en el Diccionario de Autoridades, se registra no muy rigurosamente un uso especial, sin duda derivado de su obsesivo empleo especializado vigente un siglo antes, como sustituto apelativo: "Cuidado. Se llama también la persona a quien se tiene amor» (Autoridades, 1726; I, 693).

La imagen creada tras de tal reconocimiento de una acepción significativa de cuidado que no existe ni en el léxico usual del español "estándar» actual, despeja todas las perplejidades, dejando en claro, una vez más, la asociación coincidente de los criterios históricoliterarios y ia medularidad generativo-textual en competencia con el más inmediatamente empírico de la extensión superficial. Reestablecido el esquema generativo del texto desde el valor amoroso de cuidado, resultaria la siguiente construcción:
1. (verso 14) El poeta teme más $\rightarrow$ a) sus cuidados
2. que $\rightarrow$ b) la tormenta calamitosa (nada, pronombre resumidor).
3. (versos 1-13)
Descripción de la tormenta

Se trata pues de un simple caso de hipérbaton ponderativo sentencial en la proposición compositiva básica del texto, asociando con b) un conjunto de transformaciones de desarrollo de uno de los elementos, el segundo lógico, de la comparación.

La operatividad del criterio tópico histórico-literario se descubre sin embargo sometida a un conjunto muy severo de restricciones estructu- 
rales. Lo que viene a reforzar nuestras críticas (García Berrio, 1980c), a ciertas propuestas pragmáticas sobre las convenciones literarias desarrolladas en estos últimos años, que parecen oponer un orden libérrimo, el cultural, donde priva la excepcionalidad anarquizadora, a otro sistemático y orgánico, el lingüístico. Si bien más compleja, dominada por un mayor número de variables, no deja de existir una lógica del sistema cultural operante en la literatura, ajustada y reglada por un conjunto de límites, entre los cuales hay que contar sobre todo los creados por la lengua. Por ejemplo, la lógica literaria cultural es lógica de la explicitud, lo que puede aclararse bajo la aparente tautología de que «sólo es lo que es», es decir que resulta falsa cualquier interpretación que se salga de lo que consiente la explicitud del mensaje lingüístico. Pensemos, para ilustrar lo anterior, en el caso de un tema moral de Góngora, vinculado a la construcción tópica del "carpe diem», el soneto que se inicia con un verso problemático, «llustre y hermosísima María». Existe una confusión muy generalizada que vincula la temática del "carpe diem» al género de la poesía amorosa. Nosotros probamos sin embargo (1978a), que en la lírica española dicha solución amorosa no es ni mucho menos la única, ni siquiera la preferente. El "carpe diem», desvinculada con gran frecuencia la incitación epicúrea a la dama del propio interés y goce del poeta, desembocaba en tal supuesto a una exhortación de naturaleza moral, ya que no cumplia la condíción básica convencionalizada en el código de la poesía amorosa cortés romance, postpetraquista, que identificaba poeta y amante, es decir, sujeto de la enunciación, soneto, y sujeto del enunciado, pasión amorosa.

He aquí, pues, un claro límite de explicitud lingüística operando en el seno del sistema cultural tópico que regía el cerrado mecanismo de la lírica clásica. El ejemplo del soneto de Góngora que hemos escogido, permite, incluso, establecer estrictamente las reglas del límite estructural lingüístico en las decisiones culturales. En la variante que comienza con el verso aludido, no existe ninguna indicación lingüística explícita que vincule el interés del poeta al goce personal de la pasión a que incita a la dama:

llustre y hermosísima María, mientras se dejan ver a cualquier hora en tus mejillas la rosada aurora, Febo en tus ojos, $y$ en tu frente el día,

$y$ mientras con gentil descortesía mueve el viento la hebra voladora que la Arabia en sus venas atesora y el rico Tajo en sus arenas cría; 
antes que de la edad Febo eclipsado, y el claro día vuelto en noche obscura, huya la aurora del mortal nublado;

antes que lo que hoy es rubio tesoro venza a la blanca nieve su blancura, goza, goza el color, la luz, el oro.

El presunto capricho cultural no consiente considerar amoroso este soneto, sino moral, porque en su texto explícito incumple la estructura lingüístico-actancial que determina el género amoroso. El analizador no puede, pues, hacer lo que quiere; los límites al convencionalismo cultural existen, por tanto, y son mucho más motivados y estrictos de lo que puedan suponer quienes los imaginan ajenos al conocimiento de los materiales concretos sobre los que teorizan. $Y$ esto no es una cuestión de estimación interna a un sistema concreto, el mío, que fija las condiciones. Antes al contrario, mis inventarios de condiciones son producto deductivo de la analítica empírica de los materiales textuales de la muestra. Por eso los editores de los sonetos de Góngora, de los organizadores contemporáneos de sus manuscritos, como Chacón, no incluyeron dentro de los amorosos, éste $u$ otros sonetos similares de «carpe diem», como el famoso "Mientras por competir con tu cabello», alojándolos, por el contrario, en el apartado de los morales, intuyendo la exigencia de participación del poeta-amante en el predicado amoroso, ausente en estos textos. En tal sentido, bastaría que apareciera la variante del verso inicial, el «Hermoso dueño de la vida mía», alternativa frẹcuente a "llustre y hermosísima María", para que la vinculación explícita de la dama a la persona del poeta «dueño de la vida mia»quebrara la limitación estructural, con que convertiría todo el soneto a la modalidad amorosa del "carpe diem».

1.2. El caso del soneto antes aludido, "Cosas, Celalba mía, he visto extrañas», del que ha partido la problemática examinada en el parágrafo anterior, nos pone todavía en presencia de dos cuestiones, muy vinculadas con las que venimos tratando. En él se puede corroborar:

a) Una importante alternativa a la modalidad estructural del texto soneto que hemos presentado antes.

b) Una nueva modalidad de la actuación del criterio tópico históricoliterario.

Ambas son, por lo demás, como veremos, cuestiones en íntima correlación. 
Comenzando por el primer punto, atestigua ya este texto la verificación de un hábito nuevo en la construcción textual del soneto, que fue generalizándose a medida que el entendimiento renacentista del unitematismo argumental del soneto como unidad de fábula fue dando paso a la preferencia barroca por convertir dicho unitematismo en ponderación de concepto. Obsérvese que la alternancia de estilo corresponde en Góngora a una efectiva distancia entre las fechas de la composición del soneto que comentamos, 1596, respecto a los primeros glosados con estructura lineal que hemos considerado renacentista, 1582. Años clave en la gestación del tránsito manierista a la culminación barroca, que yo vincularía en España a acontecimientos sociales de gran relieve y eco en la vida literaria, como la campaña en favor del dogma de la Inmaculada Concepción de María, acaecida en el segundo decenio del siglo XVII.

La «ponderación conceptuosa» en la estructura del texto tendrá efectos decisivos en el alojamiento textual del tema, cuya observación ha de ser máximamente pertinente en las operaciones de descubrimiento/jerarquización temática. Verdadero ejercicio de "suspense», el emisor va anticipando todos los elementos estructurales adyacentes al tema central, a manera de "pistas» para el lector, cuya corroboración final en la evidenciación temática determinaba en el poema barroco un tipo de efecto de sorpresa - maravilloso era el tecnicismo de la épocaabsolutamente análogo en casi todos sus aspectos, al sorprendido lector moderno de un relato de intriga.

Propone por tanto el soneto que estamos glosando un tipo de reso/ución temática en el terceto final, en este caso incluso exagerado al verso final, que había de alcanzar un enorme desarrollo en la práctica de los poetas barrocos españoles. Respecto a los textos de linealidad-lógica renacentista, como I y II, cuyo esquema estructural giraba en torno a una linea media de flexión que permitía estructurar análogamente tanto la continuidad del enunciado de I:

Contemplación del marco --- Salida --- No contemplación del marco como la del de II:

Actividad solar preparatoria del marco --- Salida// No salida --- Inactividad solar.

el modelo estructural barroco ofrece una progresividad a término, que desglosa progresivamente los elementos del enunciado de menor a mayor responsabilidad en la estructura funcional de la predicación. 
Esta estructura con localización del tema al final del texto, no es ni mucho menos privativa de Góngora. Antes bien se trata de un verdadero rasgo estilístico de época, vinculado a la moda barroca y que se ajusta a la peculiaridad general del sistema de construcción literaria conceptista. Participan de ella todos los demás escritores barrocos españoles: pudiendo afirmarse, incluso, que acaba siendo connatural a la estructura general del soneto barroco. Correspondiendo con esta peculiaridad temática, en el apartado de la macrosintaxis de esta teoría tipológica (García Berrio, 1980e) hemos percibido un tipo muy peculiar de construcción textual, la antidistribución, que viene a ser en realidad un caso de subrayado sintáctico de esta modalidad temático semántica (5).

(5) Ofrecemos a la consideración de los lectores el siguiente ejemplo de un texto de antidistribución de los seleccionados en Lope de Vega, autor, como Góngora, que frecuentó privilegiadamente esta modalidad constructiva:

Al sepulcro de Amor, que contra el filo del tiempo hizo Artemisa vivir claro, a la torre bellisima de Faro, un tiempe de las naves luz y asilo;

al templo efesio, de famoso estilo, al coloso del sol, único y raro, al muro de Semíramis reparo, y a las altas pirámides del Nilo;

en fin, a los milagros inauditos, a Júpiter olímpico y al templo, pirámides, coloso y mauseolo,

y a cuantos hoy el mundo tiene escritos, en fama vence de mi fe el ejemplo:

que es mayor maravilla mi amor solo.

\footnotetext{
Obsérvese que los primeros doce versos de la composición constituyen simplemente el desarrollo ponderativo-reiterativo del objeto de la sentencia básica del texto, expresado en el verso trece. En realidad el único desarrollo fundamental de la comunicación del enunciado aparece circunscrito al último terceto, con la expresión-resumidora del término de la predicación (verso 12), predicación básica textual (verso trece), y desarrollo parafrástico en paralelismo de la predicación básica (verso 14). Modalidad de construcción menos frecuentada por Quevedo, no faltan sin embargo tampoco en él depuradas muestras, como el soneto titulado "Sepulcro de su entendimiento en las perfecciones de Lisi»; aqui el desarrollo del circunstante, lugar del sepulcro de la libertad del poeta, consiste en la ponderación en retrato metafórico de las distintas perfecciones - «En este incendio hermoso (verso 1).... en esta nieve (5)... en este Oriente (7)... debajo de esta piedra (9)...) - y se extiende a las tres primeras estrofas de la composición. Siendo sólo en el terceto final donde se resuelve la frase que expresa el contenido temático del texto - «...yace mi entendimiento sepultado»; asi como su reinsistencia y delimitación en el epitafio final: "Si es su inscripción mi congojosa vida/ dentro del cielo viva sepultado».
} 
Respecto al problema de b), señalado poco antes, resulta evidente que la conciencia por parte del analista de los hechos de localización temática a que estamos aludiendo, correspondiente sin duda a la práctica consciente de los creadores clásicos, configura otra modalidad de aviso dentro del sistema de presuposición que estamos denominando tópico histórico-literario. Esa práctica de localización del tema al centro o en el final del texto acaba configurándose en auténtica regla de universal observancia, una regla textual constructiva, que simplifica las cavilaciones de selección/jerarquización, en la medida en que para casos de duda debe considerarse la posición final del texto como situación temática privilegiada, para sonetos conceptuosos; regla que puede coexistir con la de la posición medial para el caso de los sonetos expositivos de construcción lineal progresiva.

Esta regla de la posición final del tema permite resolver en la práctica numerosos casos de difícil decisión, pues en ocasiones la tendencia a ponderar artificialmente un elemento secundario del texto desembocaba en modelos de construcción textual muy deficiente, que se revelan problemáticos a la hora de su concreta localización tipológica. Un texto de Fernando de Herrera puede ilustrar nuestras consideraciones. Se trata del 215, "Las hebras, que cogia en lazos d'oro» (6), soneto muy mal construido y deficiente, donde sólo la teśis de la autoría de Pacheco, de aceptarse, podría salvar la responsabilidad de un prestigio como el de Herrera. Tras la ponderación de la hermosura a través del «retrato» en

(6) Compruébese nuestras afirmaciones a la vista del texto mencionado:

Las hebras, que cogia en lazos d'oro con arte vuestra blanca i tierna mano, mirava; i el semblante altivo i llano; i la florida luz; qu'amando adoro.

Creia, en vos d'el sacro, ecelso coro qu'el esplendor s'unia soberano; por qu'en sombra, aunque bella, i trage umano no vio tal bien el orbe $i$ tal tesoro.

Cuando rompistes leda el dulce espanto; que de vos parte ausente i solo apena, preguntando; que fuerça $\mathrm{m}^{\prime}$ arrebata?

Yo, que temo partirme, suelto en llanto, digo; pienso, qu'a muerte me condena d'el cruel vuestro amor la saña ingrata. 
los cuartetos, la difusa mención de un acto de resolución por la dama en el primer terceto, lo que insinúa el tema de «peripecia», se resuelve en el tema de la queja vehemente de la dama $\left(4, b_{1}\right)$, que por su alojamiento en la posición final permite conjeturarlo como tópico temático. Por lo demás, si bien se reflexiona, la lógica del enunciado y la estrategia de la enunciación no se ven contradichas por la aplicación de la regla de construcción textual al caso de este texto. En efecto, la ponderación de la hermosura en presencia (cuartetos) y la amenaza de su pérdida (primer terceto) desembocan lógicamente en la angustia extremada hasta la muerte (segundo terceto).

A lo anterior quizás pueda invocarse la objeción de que resultaría un proceso igualmente lógico la inversión de la secuencia parafrástica que haciamos antes; es decir: Quejas/peripecia/ponderación. Lo que, si bien es cierto de un modo general, puede oponerse a la realidad textual explicita creada por el punto de vista del emisor, cuyo hábito constructivo en el caso del soneto nos hace inferir la regla métrica. Por principio no hay duda de que los tres temas coincidentes en este texto podrían haber sido dispuestos y desarrollados en modo que cada uno de ellos fuera, en tres textos distintos, tema central. Pero aquí hay que contar con el hecho de que la focalización del emisor crea un efecto de orientación determinada del tema (Longacre, «subject matter oriented», 1976), que determina consecuencias comunicativas distintas, resueltas con acrecentamiento del énfasis de un grupo de materiales temáticos sobre los demás grupos. A las consideraciones generales para definición del tema principal o tópico del texto (2.1) hay que añadir la decisión de focalización a cargo del emisor, que, creando el ya aludido efecto de orientación, resulta decisivo para la resolución privativa de un tema en el texto como tema central en detrimento de los otros. No se olvide, en último término, que el texto de un soneto es un objeto histórico por definición como cualquier otro objeto, es decir, su esquema o marco textual se presenta abierto en principio a cualquier forma de realización que cumpla sus reglas de marco - por ejemplo no ser treinta endecasílabos, o catorce pentasílabos - ; pero absolutamente cerrado en el mismo momento en que el autor, al llenarlo de una determinada manera, lo convierte en un hecho histórico dado para el análisis, donde no es lícito ya para el analista inventar reglas «a posteriori», sino tratar de reestablecer las que siguió de modo preciso el creador, como condición «a priori» de la realización.

Se trata, en suma, de no olvidar el principio básico del análisis ideal, que pese a sus apariencias de verdad casi tautológica, es olvidado no 
obstante muy frecuentemente; en tal sentido un texto es sólo lo que es, es decir lo que ha querido hacerle ser su emisor para que sea incorporado exactamente en su ser por los receptores (Hirsch, 1973: 11 y ss.). El caso del texto abierto o del texto intencionalmente ambiguo en la escritura clásica es un objeto raro, refugiado en todo caso en el esoterismo de determinados géneros y momentos, que no son los que nos ocupan aquí. El mito reciente de la "obra abierta», demasiado extendido objetualmente en los últimos años, supone sobre todo el cambio introducido por la teoría del receptor, y la moda lúdica de la ambigüedad en el receptor moderno. En suma, nuestros sonetos en lo que al tematismo se refiere no son textos abiertos. Pero, claro está que, si el lector lo desea, puede llegar a convertirlos relativamente en tales; la condición sin embargo es que ignore, deliberadamente o por impotencia simple, los efectos del sistema de reglas de construcción, como ésta de la regla textual de construcción o regla métrica; pero en tales casos el propio receptoranalista se convertirá en gran medida en co-creador, ideal tan acariciado por los críticos modernos solícitamente convocados desde Barthes en defensa de su estatuto como sin duda temido por los artistas clásicos, que sin duda soñaron con un receptor lo suficientemente culțo y agudo que alcanzara el prodigioso destino de restituir al texto, con cada acto de lectura, la intención significativa y comunicativa del autor.

1.3. Las dos variedades de localización textual temática mediante la regla textual constructiva constituyen un paradigma, al que se ajusta sin embargo con variantes la casi totalidad de los sonetos. De una parte la generalización de la construcción barroca del soneto con tema explícito en el final no llegaba siempre estrictamente a la realización extremada de los ejemplos anteriores. Muy comúnmente esta intensificación en final de la tensión comunicativa resuelve dos expedientes distintos ajenos al caso estricto de las operacionés de determinada jerarquización. La intensificación comunicativa puede obedecer también:

a) A intención de simple reinsistencia o síntesis del tema central desarrollado en la totalidad o la mayor parte del cuerpo textual del soneto.

b) A voluntad de efectismo conceptuoso ajeno a la localización temática.

A su vez hemos de considerar también el caso de c), modalidades expresivo-temáticas, como las narrativas, que ofrecen resistencia, por su misma índole, a la concentración o concreción local textual temática, tratándose de variedades de realización de estructura temática expandi- 
da; y análogamente otros tipos, como el de los textos de peripecia, comúnmente narrativos de obligada localización medial del tema, por imperativos de la organización lógica del enunciado.

Los casos de reinsistencia final de un tema difuso en el cuerpo del texto son frecuentes. Quevedo, por ejemplo, prodigó en el Canto a Lisi un tipo de construcciones textuales donde el último terceto resulta ser una especie de cifra o moraleja universal, que resume y comprime el desarrollo temático del texto. Recordemos por ejemplo el soneto titulado "Amor de una sola vista nace, crece y se perpetúa», que, como puede el lector comprobar, cumple las condiciones descritas:

Diez años de mi vida se ha llevado en veloz fuga y sorda el sol ardiente, después que en tus dos ojos vi el Oriente, Lísida, en hermosura duplicado.

Diez años en mis venas he guardado el dulce fuego que alimento, ausente, de mi sangre. Diez años en mi mente con imperio tus luces han reinado.

Basta ver una vez grande hermosura; que, una vez vista, eternamente enciende, $y$ en l'alma impresa eternamente dura.

Llama que a la inmortal vida trasciende, ni teme con el cuerpo sepultura, ni el tiempo la marchita ni la ofende.

El tema de la proclamación perseverante y su causa, que es el fundamento inmaterial del verdadero amor, así como el de la espiritualización muy vinculado, como es sabido, a la temática de Quevedo, presentados en términos de incidencia personal y autobiográfica en el resto de la composición, se proyectan a cifra universal y despersonalizada en el terceto final, que resume y sanciona como reinsistencia sintética el contenido temático del texto.

El hábito barroco de construcción producía igualmente el supuesto enunciado en b), que como el anterior no obedece a la regla de localización temática en final, pero si responde a un evidente reflejo del caso general. La tendencia a situar en el final de la composición con el desenlace conceptuoso la carga temática central del texto, reforzada a ve- 
ces como sabemos por la construcción macrosintáctica, se resuelve con frecuencia en efectos de énfasis exclamativo o en figura de poderoso efectismo, tales como retruécanos, antítesis, paradojas, etc... Véase una muestra en el soneto de Góngora al Duque de Feria.

Al Duque de Feria, de la Señora Doña Catalina de Acuña

Oh marinero, tú que, cortesano,

al Palacio le fías tus entenas, al Palacio Real, que de Sirenas

es un segundo mar napolitano,

los remos deja, y una y otra mano de las orejas las desvía apenas; que escollo es, cuándo no sirte de arenas, la dulce voz de un serafín humano.

Cual su acento, tu muerte será clara, si espira suavidad, si gloria espira su armonía mortal, su beldad rara.

Huye de la que, armada de una lira, si rocas mueve, si bajeles para, cantando mata al que matando mira.

La reinsistente instancia, con el modelo mítico de Ulises y las sirenas, al abandono de los encantos de doña Catalina de Acuña, cumple la etapa correspondiente al terceto final, sin que suponga otra novedad de sorpresa o deíxis temática, que el retruécano en espejo del último verso.

La modalidad textual antes indicada en el apartado c) supone un caso de inevitable ruptura con el esquema general básico de la localización temática en final del texto propia del modelo barroco de construcción. Adviértase no obstante que lo proponemos a título de muesta de cómo el esquema constructivo temático no es absolutamente libre, sino dependiente de la propia lógica del enunciado. Así en la narración, recordemos cómo el nudo conśtituye la parte medial temática, respecto a la que se articulan congruentemente la presentación y el desenlace. Aquellos casos de proyección lírica en el soneto de estructuras temáticas narrativas no alteran la estructura de su modalidad expresiva básica. Aun en textos en los que, por la fecha de la composición, podemos suponerlos vinculados a la práctica personal de la construcción barroca, 
de Góngora por ejemplo, con tema en posición de coda textual, tal inserción no subvierte sin embargo la práctica usual lógica de la composición. Recordemos el caso del famoso y bellisimo soneto narrativo: "Ya besando unas manos cristalinas", y no olvidemos que la índole inexcusablemente narrativa de la situación temática indujo a Góngora a tratar el mismo tema a través del modelo métrico compositivo más genuinamente narrativo, el romance, en el también bellisimo: «Servía en Orán al reyl:

Ya besando unas manos cristalinas, ya anudándome a un blanco y liso cuello, ya esparciendo por él aquel cabello que Amor sacó entre el oro de sus minas,

ya quebrando en aquellas perlas finas palabras dulces mil sin merecello, ya cogiendo de cada labio bello purpúreas rosas sin temor de espinas,

estaba, oh claro sol invidioso, cuando tu luz, hiriéndome los ojos, mató mi gloria y acabó mi suerte.

Si el cielo ya no es menos poderoso, porque no den los tuyos más enojos, rayos, como a tu hijo, te den muerte.

La descripción de las caricias en la entrevista galante, seriadas mediante la anáfora distributiva con ya, se dilata hasta el final de los cuartetos; $y$, como es habitual en la estructura medial, el inicio del primer terceto marca el centro temático de la secuencia narrativa, acertadamente sintetizada por Vicuña, con esa especie de acierto felicísimo de los editores y comentaristas contemporáneos de Góngora o Quevedo para la síntesis textual manifiesta en rótulos y títulos: «Al sol porque salió estando con una dama y le fue forzoso dexarlan. El desenlace lógico, imprecaciones al sol inoportuno, se incluye en el tercerto final.

Si en el caso anterior se trata de un texto gongorino temprano, fechado por los editores en 1582, y por tanto puede argumentarse que la situación medial del tema responde, más que a la índole narrativa de la resolución temática mediante la cual yo he explicado la peculiaridad constructiva, a la práctica usual en el primer Góngora, más apegada al es- 
quema renacentista; veamos cómo la misma solución de la localización temática central se registra idénticamente en un texto muy tardío, de 1621, plenamente consolidada ya la práctica barroca de Góngora. Se trata del siguiente soneto:

Al tronco Filis de un laurel sagrado reclinada, el convexo de su cuello lamia en ondas rubias el cabello, lascivamente al aire encomendado.

Las hojas del clavel, que había juntado el silencio en un labio y otro bello, vïolar intentaba, y pudo hacello, sátiro mal de hiedras coronado;

mas la invidia interpuesta de una abeja, dulce libando púrpura, al instante previno la dormida zagaleja.

El semidiós, burlado, petulante, en atenciones tímidas la deja de cuanto bella, tanto vigilante.

También en este caso el epígrafe más generalizado entre los editores se anota el mismo acierto inconsciente de adecuada sumarización e individuación del tópico textual central: «A una dama que estando dormida la picó una abeja en la boca». Efectivamente el tema concreto es el tan tópico y frecuentado del pinchazo, picadura o en ocasiones sangría, dentro de la variedad temático-narrativa que yo he definido (García Berrio, 1978) como peripecia. La iniciación temática de los cuartetos con la descripción del marco bucólico de la escena y la ficción de las intenciones libidinosas del sátiro respecto a la dormida ninfa Filis, no es otra cosa que la propuesta de la obligada transposición galante del acontecimiento, trivial y hasta vulgar en el plano real, según era uso habitualizado en esta modalidad temática de la poesía cortés, la peripecia, tan próxima cuando menos a las más festivas composiciones conmemorativas como a las amorosas serias. La picadura de la abeja y el despertar de la zagala, localizados precisamente en el primer terceto, centro usual de localización temática central, supone la afloración del acontecimiento real; dando paso, en fin, al nuevo episodio de transferencia ficticia con la imaginaria fuga del sátiro sorprendido.

Ya se ha dicho cómo este texto tardío, en pleno momento barroco, supone un caso de mantenimiento del primer esquema renacentista de 
ubicación temática. No puede atribuirse a descuido, infracción o recuperación estilística contra corriente, deliberadamente proyectada por Góngora. Como ya he indicado, se trata de una muestra de cómo la modalidad de construcción y distribución temática en estos textos del Siglo de Oro no se muestra autónoma de las exigencias de coherencia impuestas por la naturaleza de las distintas variedades expresivotextuales. En los dos ejemplos presentados, la lógica de la narración imponía el esquema de organización textual de linealidad progresiva, que sitúa el tópico o tema central narrativo en la posición medial textual del primer terceto. Puede constatarse, no obstante, que el paulatino dominio del hábito estructurante barroco se traduce en el progresivo abandono de aquellas modalidades expresivo-textuales, como la narrativa, incompatibles con la referida práctica de disposición temática,y construcción textual. Ello es efectivamente cierto, y en autores como Góngora y sobre todo Lope de Vega, que cultivaron la espúrea modalidad textual de la narración lírica en sonetos, se precisa - a primera vista al menos - la misma progresiva propensión al abandono de las estructuras narrativas. El caso de la narración de peripecias, temática a la que corresponde el segundo de los ejemplos mencionados, podrá suponer, desde el punto de vista anterior, una especie de fórmula de compromiso. La inabdicable condición narrativa de los textos con dicha temática, se veía en cierto modo paliada por la condición de mínima extensión de la acción, peripecia momentánea, gesto brusco, etc..., así como por sus posibilidades inmediatas, requerida incluso por la índole de este subgénero, de ponderación y transferencia a moralejas conceptuosas más específicamente lírico-galantes.

1.3. Un último caso cabría plantearse entre aquellos en los que la localización temática del tópico textual central viene casi obligadamente establecida por la índole especifica del tema y la construcción. Se trata de la disposición medial en el texto de la explicitación temática en los sonetos que presentan lo que hemos denominado modalidad expresiva de símil (García Berrio, 1978: 34-36). Como he dejado de manifiesto, son muy numerosos en el Siglo de Oro los textos que presentan esta peculiaridad elevada a rango de definidor de la macroestructura; si bien con posterioridad a mis primeros trabajos, en remodelaciones aún inéditas, pero de las que he anticipado sinopsis (García Berrio, 1979; 1981) he modificado muy sustancialmente mis decisiones sobre el nivel de la inserción del símil como modalidad expresiva en el esquema de producción y de representación del texto, así como en lo que se refiere, consecuentemente, a su disposición en la esquematización congruente y económica de la teoria tipológica en general. 
Aunque el tratamiento monográfico de los problemas del símil dentro de una teoría tipológica continúa siendo una de las cuestiones importantes todavía aplazadas dentro de mis trabajos, de tal reflexión ha de seguirse seguramente una verdadera tipología interna de las distintas variedades de su resolución textual.

Aun cuando el número y diversidad de los tipos de símil textual que puedo prever desde mis materiales actuales, hacen seguramente de él un fenómeno complejo y variado; podemos asumir provisionalmente una imagen relativamente media y unitaria del mismo, a fin de indicar lo pertinente en punto a la actual problemática de la determinación temática. El caso sin duda más general de símil determinará, como la narración, una localización en posición media textual de la explicitación temática central. Lo que resulta fácilmente comprensible si pensamos que la existencia de dos cláusulas mayores del soneto - cuartetos vs. tercetos-propicia la distribución entre ellas de los dos elementos de referencia, real y metafórico o viceversa, del símil. Tomemos, para ilustrarlo, otro ejemplo del mismo Góngora:

No destrozada nave en roca dura tocó la playa más arrepentida, ni pajarillo de la red tendida voló más temeroso a la espesura;

bella ninfa la planta mal segura no tan alborotada ni afligida hurtó de verde prado, que escondida víbora regalaba en su verdura,

como yo, Amor, la condición airada, las rubias trenzas y la vista bella huyendo voy, con pie ya desatado,

de mi enemiga en vano celebrada. Adiós, ninfa crüel; quedaos con ella, dura roca, red de oro, alegre prado.

En el texto propuesto la base de comparación extendida por los cuartetos bajo ejemplos reiterados subrayados por la fórmula comparativa: «no nace... más arrepentida/ mi pajarillo... más temerosa/bella ninfa... no tan alborotado hurto"s se transfiere en los tercetos al propio caso per- 
sonal, explícitamente subrayado en el gozne mismo de la estructura textual al inicio de los tercetos mediante la apódosis comparativa como yo.

2.0. Establecida en los parágrafos anteriores la peculiar condición de unitematicidad del texto del soneto, así como los principales tipos de distribución y localización del tema dentro de la estructura textual de la referida estrofa, pasemos ahora a considerar ya los problemas relativos a su conceptualización y definición. En principio podemos aceptar como definición genérica de tema la que puede sugerir su funcionamiento usual en la crítica literaria formal, única disciplina científica que por razones de sobra conocidas se ha preocupado con alguna asiduidad de esta cuestión, y que, sin llegar quizás a plantearse el problema de la definición, opera con una evidentemente adecuada caracterización del tema. En tal entendimiento, tema sería una condensación semántica en el seno de un texto susceptible de constituir en el proceso de la comunicación una unidad de discurso aislable y sustantiva, conscientemente emitida y recibida como tal. Esa misma condición de condensación, que implica en nuestro entendimiento una clara cohesión significativa en torno a un núcleo unidad y centro de sentido, así como la acotación estricta de sus límites significantes en el seno del discurso, dota al tema de una evidente capacidad funcional en el interior del texto; y es esa funcionalidad la que indirectamente permite la caracterización de cada uno de los temas que se coaligan para constituir cada unidad de discurso.

Desde la anterior definición del tema, válida para todas las posibles acepciones reales de la denominación, debemos pasar en nuestro caso a considerar la relatividad de la noción tema. La definición genérica del tema en términos funcionales de límite, relación dialéctica e interacción semántica, evidencia la imprescindible asunción de que en cada extensión habitual de discurso coexisten varios temas constitutivos de texto. Sin embargo, en otro nivel, decimos que cada una de esas extensiones viene caracterizada por un solo tema o tópico del discurso. En tal sentido se hace imprescindible distinguir quizás entre tópico como tema único textual, y tema, como unidad semántica funcional-constitutivo parcial de texto, distinción que resulta inédita en lingüística, con todos los inconvenientes de su novedad por tanto. Quizás menos equívocos suscita la diferenciación entre tema central, o si se quiere tema del texto, y tema o temas secundarios o marginales, constitutivos funcionales del texto. En nuestra tipología hemos actuado siempre desde la consideración intuitiva de las dos modalidades, procediendo a las operaciones de tipologización, a través de la determinación del tema central, y propo- 
niendo la definición de cada texto en el plano temático como la suma del tema central y los temas secundarios que componen el conjunto textual (7). En tal sentido, si el tema central establece el requisito diacrítico en la tipología temática, son los temas secundarios los determinantes diacríticos últimos en la definición de cada texto dentro de la categoría tipológica.

Adelantemos que la condición últimamente diferencial del tema central de un texto respecto a los temas secundarios radica, como hemos indicado desde las primeras exposiciones de nuestra teoría, en la condición de dominancia lógico-lingüistica de la enunciación básica del tema principal respecto de los enunciados básicos de los temas secundarios, determinados por la orientación aportada al texto por la focalización temática del emisor, factor comunicativo no contradictorio con la condición objetivo-textual, de dominancia, como indicábamos antes (1.2). Esta condición puede corresponderse en la manifestación lineal textual con una mayor extensión del dominio del tema en términos de significante textual. Sin embargo ya hemos visto cómo en numerosas excepciones, casi siempre producto de intencionalidad estilística en el caso de los sonetos, la dominancia básica generativo-textual del tema central aparece enmascarada por una mayor extensión superficial de un tema secundario. El tipo de relaciones subordinativas entre los enunciados sintéticos de los diferentes temas en el interior del texto, responde sustancialmente a los mismos órdenes y modelos que esquematizan las relaciones de frases simples en la teoría tradicional de la oración compuesta (G. Rojo, 1978), superados obviamente los condicionamientos más superficiales, impuestos por las diversas alternativas de realización morfosintáctica del mismo tipo de relación profunda sintácticosemántica. En este sentido he de remitir para el texto a mi convencimiento de la absoluta isomorfía de la funcionalidad lingüística en todos

(7) Los principios generales de la jerarquia lingüistica (Longacre, 1964: 16-17, 21; 1965 : 73; 1970; 1976: 255 y ss.) son aplicables a la organización temática interná del texto. La jerarquia temática textual tiene como nivel más bajo el conjunto constituido por los temas secundarios (o temas), sobre el cual se dispone el nivel del tema central (o tópico); esta estructuración jerárquica se mantiene incluso en el caso de interdependencia temática, ya que la focalización que realiza el emisor en los textos caracterizados por este tipo de relación funcional da como resultado que la organización temática quede de un modo y no de otro - que sería igualmente posible - en el caso de cada texto concreto. La serie de dos elementos jerarquizados constituida por los dos niveles anteriormente mencionados queda dominada jerárquicamente por el nivel superior que forma el conjunto temático textual, suma de tópico y temas. La jerarquía temática pertenece al ámbito macroestructural del texto y por medio del componente de transformación textual puede ser manifestada en la superficie textual de diversos modos. 
los niveles del lenguaje (Petöfi-García Berrio, 1979), lo que paradójicamente atenta directamente contra la realidad lingüística de los niveles, precisamente en la medida que los potencia como integrantes metalingüísticos elocuentes en la figuración del modelo.

En efecto, la observación de las distintas modalidades, posibles $y$ reales, a propósito de la combinación de temas que se siguen de los trabajos de jerarquización desarrollados para esta teoría tipológica, confirman también en el nivel de las relaciones textuales intertemáticas la hipótesis de la isomorfía funcional del lenguaje formulada por mi hace tiempo en el dominio de la integración de frases simples en la frase compuesta (García Berrio, 1970). La primera hace equivalente el texto del soneto a una frase simple o proposición elemental; ya que el tema único, formulado a través de una sola predicación básica y tipologizado a través de un rótulo nominalizador no presenta ninguna realidad relacional. Respecto al texto pluritemático, pueden darse los mismos tipos funcionales que en los demás niveles; a saber: a) relación entre una constante y una variable, b) relación entre dos constantes, c) relación entre dos variables; entendiendo obviamente por constante por relación. al texto el tema caracterizado como central, y por variable/s al tema/s caracterizado/s como marginal o secundario. la verificación del cumplimiento de tales hechos también en el funcionamiento de la estructura temática del nivel textual no constituye ningún género de sorpresas, si se tiene en cuenta que nuestro planteamiento de 1970 constituía a su modo, un establecimiento teórico "a posteriori» de un conjunto de datos analíticos previos. Se trataba en cierta medida de una tipología sentencial, absolutamente análoga y predecesora de la tipología textual que hemos venido desarrollando después.

$\mathrm{Si}$, como en la teoría sentencial de referencia, utilizamos para la designación de las funciones temáticas en el texto, las mismas denominaciones glosemáticas de las funciones lingüísticas, tendremos los siguientes tipos:

a) Determinación, relación entre un tema-tópico textual dominante y un tema o temas marginales. Las condiciones respectivas de centralidad y marginalidad de los temas en este caso quedan claramente establecidos por la naturaleza de la construcción textual. Sentencialmente equivale a tipos de relación oracional adjetivo-calificativa, o completiva.

b) Interdependencia, relación entre dos temas que mantienen entre sí implicación recíproca. Las condiciones de centralidad y marginalidad de los temas en el texto quedan sólo establecidas en función de reglas con- 
vencionales especificas. Su equivalente oracional serian las frases del tipo prótasis-apódosis, tal como causales, condicionales, comparativas.

c) Constelación, relación entre temas que no presentan ningún tipo de vinculación; coexistiendo por tanto en el texto sin que pueda afirmarse la centralidad o marginalidad de ninguno de ellos. Equivaldrían oracionalmente a los tipos puros de parataxis, copulativa, disyuntiva y distributiva.

De los tres tipos temático-funcionales que estudiaremos detenidamente en apartados sucesivos (determinación, 2.2. y 2.3., interdependencia 2.4 y ss.), la clase que impone la práctica más aproblemática para las operaciones de jerarquización temática es sin duda la determinación. La dependencia temática en este tipo de textos resulta evidente, y el tema o temas marginales se presentan como claras expansiones transformativas de los componentes básicos de la predicación del tema central, actanciales en las variedades adjetivo-calificativas y del funtor en el de las completivas. Ya hemos indicado la condición forzadamente más problemática de la jerarquización temática en el tipo funcional creado por la interdependencia; téngase presente que lo que aquí se califica de principal-subordinado en la teoría tradicional de la frase compleja, o de central-marginal en la teoría temática, no son variables que lo sean así por su misma naturaleza lógica, como acaece en la determinación. En la fijación del tipo relacional causal o consecutivo, por ejemplo, la decisión depende básicamente de un hecho formal determinado en función del foco. Así: «el instrumento se rompió / porque / se usaba mal» (causal) ofrece una de las modalidades posibles de representación, la causal, de una mismá predicación relativa causalconsecutiva; la modalidad de formalización consecutiva de la relación aporta sólo una modificación del foco: «El instrumento se usaba mal, tan mal / que se rompión.

Por lo que se refiere a la relación temática de constelación, queda descartada por la propia naturaleza textual del soneto. La constelación de temas no puede tener entrada en un tipo de texto que es unitemático por definición. La unidad de concepto del soneto establece la vinculación adyacente de los temas secundarios a un tema central bien perfilado y distinto, como en el caso de la determinación, o a una constitución temática plural pero unitaria, pues que los componentes aparecen comprometidos en íntima solidaridad lógica, en el caso de la interdependencia. La constelación temática resulta sólo relativamente posible. Puede darse en textos de gran extensión, como el romance o la novela, 
en determinado nivel, con la condición de que ese nivel no sea el más profundo. La estructura del tópico textual destierra por definición el modelo constelado de construcción, en la medida que el mismo atenta directamente contra la unidad textual. Aun en el nivel frástico la parataxis más simple como: "Pedro estudió inglés y Ana ha aprendido a conducirn presenta la opción de representar dos textos diferentes, o el sumario de los mismos, a menos que se establezca una formulación o sumario textual, del tipo "Actividades veraniegas de Pedro y Ana", "Ocupación de Pedro y Ana después de su separación», o «...en la espera de su encuentro", etc... En tal sentido puede afirmarse que la parataxis profunda constituye marca textual diacrítica, en la medida en que establece una marca delimitativa en el discurso.

La construcción de constelación en el texto del soneto es sólo posible: a) como marca funcional de los temas secundarios entre sí; b) en casos de reduplicación, disyunción o repartición de algún componente de la predicación textual primaria; y c) en casos de reduplicación parafrástica del enunciado temático total. El primer tipo se hace presente en casi todos los casos de textos constituidos bajo la estructura funcional de la determinación adjetiva. Normalmente los desarrollos temáticos secundarios, metafórico-transformativos, de los distintos elementos constitutivos del uretrato» presentan entre si una solidaridad aditiva explícita o implícita del tipo de la indicada. El tipo segundo se da frecuentemente en estructuras como el galanteo, donde se establece un "crescendo" de predicaciones no totalmente sinónimas del funtor predicativo básico, "cantar», "celebrar» o «ensalzar». Los casos correspondientes al tercer tipo no son muy frecuentes; su distancia al texto mal construido es demasiado corta para quie el riesgo no los haga indeseables. La garantía de brillantez - de éxito comunicativo del texto, en otros términos, como tal texto artístico - en tales casos la establece el grado de acierto parafrástico de la reiteración. Uno de los más bellos y famosos sonetos españoles tiene esta peligrosa estructura, superada sobre todo por la maestría del autor en el dominio de la construcción microtextual, se trata del texto de Quevedo «Cerrar podrá mis ojos la postrera», con una repetición en cuartetos y tercetos del tópico textual "Amor constante más allá de la muerte» sobre dos planos distintos de consideración, trascendental y somático.

Obviamente que aun en el caso del soneto es posible encontrar y construir textos con función intertemática de constelación que no responda a ninguna de las salvedades anteriores. Un soneto puede en efecto tratar primariamente de dos cosas diferentes, sin establecer ninguna vinculación entre ellas. Pero es, entonces, el caso del soneto falli- 
do, pluritemático, con varios "conceptos-fábula», tal como lo proscribían precisamente los teorizadores clásicos del género y como lo evitaban los artistas, que sólo raramente se deslizaban en un error de tales dimensiones. Por su relativa brevedad, el soneto era el texto más idóneo para la concreción temática, que debía explicitar indefectiblemente el subrayado textual unitario del discurso encerrado en él a través de la presencia de un único tema central, de una sola constante de contenido, lo que descarta a la constelación como modalidad funcional que vincule al tema central; ya que, de darse, no podria relacionar a la constante temática central del texto sino con otra constante, absurdo que descompondría la entidad unitextual del soneto.

2.1. Los intentos tradicionales de definición del tema adolecen, a mi juicio, de una indistinción sustancial entre:

a) Los integrantes del tema, vinculados a la estructura funtorial y actancial de su predicación de base.

b) Las condiciones de modalidad expresiva, directa o indirecta, de la predicación.

c) El componente propiamente semántico del tema.

Creo que sólo tras nuestros trabajos de tipologización temática se presenta como realidad fácilmente hacedera el deslinde y la subsiguiente asunción conceptual de los anteriormente aludidos constituyentes parciales del tema. Incluso por si mismo, inicialmente, el tema se presentaba como el mismo oscuro conglomerado de elementos sintácticosemánticos, que legaba la tradición lingüística y crítica. Sin embargo, como consecuencia de mis trabajos, resulta ya evidente que, por lo pronto hablar hoy del tema "amoroso" de un soneto, por ejemplo, es absolutamente insuficiente. La condición amorosa es un primer registro temático, determinado básicamente por la naturaleza del funtor predicativo en la base del tema central del texto referido. Explicitamente representado en la estructura textual de superficie a través de lexemas pertenecientes al campo amoroso, o mediante relaciones sintácticosemánticas que impliquen presuposiciones relacionadas con dicho campo, nosotros no confundimos usualmente un soneto o canción amorosos de Herrera con su canción a la pérdida del rey don Sebastián de Portugal, por ejemplo.

Una serie de posteriores verificaciones en la estructura funcional- 
actancial de la predicción básica del tema, va perfilando aquel primero, con sucesivos registros temáticos. Si se tiene en cuenta la progresión de rangos o niveles en nuestra esquematización de la tipología temática (García Berrio 1978, o bien 1979), a partir del primer nivel de la fórmula inicial, que nos ofrece el esquema funcional (el poeta ama a la dama) determinante del que hemos denominado primer registro temático, van apareciendo sucesivos registros siempre derivados de las virtualidades funcional-actanciales implícitas en la base temática; por ejemplo la presuposición de correspondencia en el actante objeto determina la peculiarización temática del canto amoroso, o la quejasufrimiento en el nivel segundo. Sucesivamente, el nivel tercero, vinculado a la especificación actancial, determina mayores cotas de explicitud y concreción en el enunciado del tema; ya es posible, por ejemplo en el tema de la queja amorosa, distinguir como subtemas la queja amorosa de la dama, frente a la de sí mismo, o la del eufemismo del Amor. Sucesivamente, podemos ir explicitando nuevas circunstancias temáticas, como la de que la queja amorosa de la dama se realiza en apelación directa o a través de un confidente, que se signifique o no mediante un desarrollo temático adyacente de algún circunstante, de lugar -marco, paisaje, ausencia - o de tiempo, etc... En niveles sucesivos, cuarto en nuestra esquematización de 1978 y modificado después (1979), la modalidad expresiva permite que conectemos temas en oposición superficial textual diferentes, como una misma realidad temática con la modificación de una transformación textual de símil; señalemos como ejemplo muy significativo la equivalencia semántica profunda entre las variedades de realización del tema de la degradación de la hermosura, expresado de modo directo en los sonetos de "carpe diem», e indirecto en los de la "caducidad de la rosa".

A todo lo anterior, que corresponde a los apartados a) y b) de nuestro esquema precedente de los constituyentes parciales del complejo temático, ha de a ñadirse el apartado c), el más aparente y tradicionalmente consciente componente temático, al punto que en la compleja amalgama de elementos indiscriminados que suelen convocarse bajo la idea global del tema, este tercer conjunto de elementos semánticos pasa a constituirse conscientemente en la casi exclusiva sustancia temática, de donde resulta la tradicional vinculación del tema casi estrictamente al dominio semántico. Sin embargo la discriminada disección de los constituyentes temáticos que se sigue de nuestra elaboración y esquematización de una tipologia de fuerte base generativo-textual, permite restituir al tema su compleja condición sintáctico-semántica, a través de la consciente imagen de la acción de los subcomponentes a) y bl. 
La inserción del componente semántico c) en la estructura sintácticosemántica del tema, incorporada por a), se realiza como ampliación o valencia especificada del funtor de la predicación básica. Pensemos, por ejemplo en las seis terminales temáticas en que se resuelve el canto a la dama en nuestra esquematización de 1980 . La proclamación $\left(4_{1} a_{1}\right)$, que incluye la pura y simple declaración de amor y la promesa de perennidad en la pasión amorosa, constituye el tema más aliviado de carga semántica adherida a la idea temática general de canto a la dama. La glorificación $\left(4_{1} \mathrm{a}_{2}\right)$ añade básicamente la justificación del canto a través de la ponderación de la virtud de la dama; finalmente el galanteo $\left(4_{1} a_{3}\right)$ supone una intensificación vibrante de la expresión positiva que es el canto. Las terminales temáticas dominadas por el nudo que hemos designado con el nombre genérico de presentación $\left(4_{1} a_{2}\right)$, se caracterizan frente a los tres anteriores por adensamiento de la carga semántica sobrepuesta a la predicación básica del canto. Así el retrato $\left(4_{1} a_{4}\right)$ sedimenta y localiza el canto en la ponderación de los rasgos de hermosura física de la dama, la sublimación $\left(4_{1} a_{5}\right)$ especializa la mención de que el canto no viene justificado en ninguna gracia material de la señora sino en cualidades o trasparencias de índole espiritual. Finalmente la peripecia $\left(4, a_{6}\right)$ aprovecha una fútil anécdota adherida, para ponderar el objeto del canto, magnificando la proporción. Como evidencian todos los ejemplos anteriores, la inserción de la carga semántica resulta evidentemente soportada por el functor de la predicación básica.

En conclusión, proponemos como definición o caracterización del tema central del texto (8), el resultado de la inserción de un componente semántico cl, tradicionalmente considerado tema, en una estructura sintáctico-semántica de constitución predicativo-actancial a), que determina la clase temática, expresada en términos de unas determinadas modalidades expresivas b). Esta distinción de clase temática -amor, correspondencia, canto, canto a la dama, etc... - y tema - retrato, glo-

(8) La estructura sintáctico-semántica determinante de la clase temática textual está constituida por un esquema predicactancial en el que un predicado relaciona unos actantes; para representar esta relaciọ́n nos servimos en nuestros trabajos tipológico-textuales de las estructuras de funtor (Lehrberger, 1974). En el estudio de las tipologias textuales nos ha sido muy útil la teoría predicactancial, así como la con ella tarremparentada gramática de casos (Tesnière, 2 1969: 102 y ss.; Greimas, 1971: 263 y ss.; 1970: 253 y ss.; 1976; Fillmore, 1968; 1971; 1977; van Dijk, 1972; 130 y ss.; Heger, 1976: 102 y ss.; 1977; Longacre, 1964: 35; 1976: 23 y ss.; Weinrich, 1981; Ramón Trives, 1979: 188 y ss.; HallidayHasan, 1976: 43 y ss.; Petöfi, 1973: 230; Heydrich, 1977; 1978), que en otra dirección analítica tanto han contribuido al estudio de las macroestructuras narrativas (Todorov, 1968; García Berrio, 1973; 207 y ss.; Vera Luján, 1977). 
rificación, peripecia, etc... - en el interior de la noción tradicional significada por esta segunda denominación creo que resuelve numerosos equívocos, tanto en lo que se refiere a la posible insatisfacción de proponer la formulación de algún nivel de la clase temática como tema, como inversamente a la desorientación tradicional sobre el organismo de las afinidades temáticas suscitada por la exclusiva mención del tema como mero componente semántico insertado. A su vez la predicación de base del tópico textual, explícita en el texto o implícita como presuposición en el enunciado terminal, determinaría el marco global del género temático: amoroso, moral, burlesco, etc... (García Berrio, 1982: 264).

2.2. En el apartado 2.0 estableciamos dos aspectos básicos en el tratamiento del tema sobre los que nos proponemos volver ahora, tras la previa definición del mismo realizada en el parágrafo anterior. De una parte hemos señalado la condición generalmente plural de los temas en el texto y la subsiguiente necesidad de distinguir entre el tópico temático o tema principal y central y los tópicos adheridos o secundarios. $Y, e$ segundo lugar, adelantábamos nuestra propuesta de considerar las modalidades de comportamiento asociativo de los temas en orden a la constitución textual como análogas a las que rigen las leyes de integración de frases en el discurso complejo. Presentaremos aquí ambas propuestas en su auténtica modalidad orgánica de realidades coaligadas. La ilustración de las propuestas anteriores ofrece indiscutibles peculiaridades relativas al caso concreto del autor cuyos textos se tomen en consideración; lo que viene a causar notables dificultades a este estudio, que quiere ceñirse al menor número posible de ilustraciones textuales por razones evidentes de varia economia. Sin embargo juzgamos suficientemente generalizables nuestras operaciones y conclusiones en este punto, al menos para crear un cuadro general algorítmico de los problemas mayores, a partir del cual no resulta difícil inferir cada estrategia concreta adecuada a cada caso textual concreto.

Una primera clase de textos, que se ofrecen escasamente problemáticos en las operaciones de establecimiento del tema principal y de las modalidades de vinculación al mismo de los temas secundarios, es la de los sonetos de símil. Ellos nos darán ocasión a verificar las dos modalidades básicas de la funcionalidad por determinación, consistente en la vinculación directiva de una constante, en nuestro caso el tópico temático textual, y las variables o tópicos secundarios. El símil establece por definición la proporción entre una base semántica de referencia y un «tertium comparationis». No es éste el momento de tratar cuestión tan compleja como las variedades del símil textual, que abordaremos mo- 
nográficamente en otro trabajo; pero, pese a la rica tipología de variedades de simil, la caracterización genérica antes señalada puede cubrir válidamente en lo sustancial los diferentes tipos y modalidades. De la definición se deduce, en tal caso, que la base semántica real constituye el tema central, mientras que el "tertium" incorpora el tema o temas secundario/s. De ahí que en las más recientes remodelaciones de la representación gráfica de mi modelo tipológico he optado por indicar la condición de modalidad expresiva en el último rango, secundando inmediatamente por tanto $-y$ a partir de - a la expresión semántica del tema. (Garcia Berrio, 1980a; 1981).

La prioridad directriz del soporte real temático, sobre el tematismo metafórico secundario es quizás más evidente cuanto más fragmentado y recursivo se presenta el componente metafórico en el texto. Se trata básicamente del frecuentado esquema textual que establece derivaciones metafóricas en paralelo como desarrollos transformativos de componentes discretos del componente del enunciado textual. Por ejemplo en el soneto de Quevedo titulado «Retrato no vulgar de Lisi» (9), cada uno de los lexemas que constituyen el eufemismo galante de su elemento del retrato, a su vez convencionalmente transpuestos a través de referencias íopicas indirectas: cabellos / «crespas hebras", ojos / «estrellas negras», mejillas / "rosas», boca / "clavel», etc..., va encontrando un desarrollo por expansión erfática de la metáfora, que adhiere de esta manera metáforas temáticas secundarias, fácilmente discriminables del tema central del retrato y sus partes. Otro texto de

(9) Para más comodo cotejo del lector se transcribe aquí el soneto mencionado:

\footnotetext{
Crespas hebras, sin ley desenlazadas, que un tiempo tuvo entre las manos Midas; en nieve estrellas negras encendidas, y cortésmente en paz de ella guardadas.
}

Rosas a abril y mayo anticipadas, de la injuria del tiempo defendidas; auroras en la risa amanecidas, con avaricia del clavel guardadas.

Vivos planetas de animado cielo, por quien a ser monarca Lisi aspira, de libertades, que en sus luces ata.

Esfera es racional, que ilustra el suelo, en donde reina Amor cuanto ella mira, $y$ en donde vive Amor cuanto ella mata. 
retrato metafórico, que ilustra un grado inmediatamente superior de complejidad temática, podría ser, dentro del mismo «corpus» quevedesco del Canto a Lisi, el titulado «Procura cebar a la codicia en tesoros de Lisi» (10). Aquí al tema de base, retrato y sus partes, se accede mediante un doble plano temático-metafórico: a) las riquezas del mar, símiles inmediatos de las bellezas de la dama, y b) la actividad recolectora del navegante. En cualquier caso, uno y otro esquema desarrollan el tipo de determinación calificativa o adjetiva, propias de la hipotaxis relativa y de los incisos calificativos en frases subordinadas de participio.

Junto al tipo antes expuesto en el que el componente temáticometafórico secundario queda vinculado a las distintas variables actanciales de la predicación temática directa central, se ofrece el tipo del simil textual de la predicación global, constituyendo entre ambos las dos modalidades básicas de símil con relieve temático. Aquí es un solo cuerpo temático metafórico - susceptible a su vez de estar constituido por un solo tema o un complejo temático - el que se ofrece vinculado por determinación al tema central. Obviamente la dependencia determinativa, del tipo completivo en este caso, se vincula más exactamente al conjunto general de la predicación, simbolizado por el funtor predicativo. La variable es aquí el componente no real del símil, vinculado por proporción a la predicación de la base real, la constante directriz temática. Con mucha frecuencia los conectores del símil se ofrecen explícitamente en el cuerpo textual, como en el soneto titulado «Náufrago amante entre desdenes», en el que destacamos la anticipa-

(10) Compruébese lo afirmado en el texto sobre el soneto aludido:

Tú, que la paz del mar, joh navegante! molestas, codicioso y diligente, por sangrarle las venas al Oriente del más rubio metal, rico y flamante,

detente aquí; no pases adelante; hártate de tesoros, brevemente, en donde Lisi peina de su frente hebra sutil en ondas fulminante:

Si buscas perlas, más descubre ufana su risa que Colón en el mar de ellas; si grana, a Tiro dan sus labios grana.

Si buscas flores, sus mejillas bellas vencen la primavera y la mañana; si cielo y luz, sus ojos son estrellas. 
ción temática y la mayor extensión en el significante textual - las tres primeras estrofas de la composición - del tema secundario, la descripción del naufragio; tras de la que se da paso a la expresión del tema central o correlato en la pasión amorosa, manifestado como suele ser muy usual en la posición evidenciadora del último terceto, en virtud de la que hemos denominado regla métrica o de evidencia temáticoestrófica:

Yo ansí, náufrago amante y peregrino, que en borrasca de amor por Lisis muero, sigo insano furos de alto destino.

El caso estructuralmente es absolutamente análogo cuando faltan los conectores explícitos del símil, como en el soneto «Goza el campo de primavera templada y no el corazón enamorado». Tras la descripción de los varios efectos del paisaje estival, adelantada como en el ejemplo del texto anterior a las tres primeras estrofas del soneto, se enuncia abruptamente el efecto antitético de la situación real en el último terceto:

Yo solo, joh Lisi!, a pena destinado, y en encendido invierno l'alma mía, arde en la nieve $y$ yélome abrasado.

Expresión a su vez compleja, como puede observarse, tachonada del metaforismo interior, de orden microsentencial léxico, de los tópicos de estaciones, nieve, fuego, etc... significativas de la índole pasional del sentimiento.

2.3. Estructura de organización temática semejante a la de la determinación de los sonetos de símil, puede encontrarse también en textos que no registren la presencia del símil temático. Como en el caso de la transformación de expansión en símil de uno o varios componentes del enunciado temático central no metafórico, se registran tipos.análogos de expansión en sonetos como el titulado "Ofrece a Lisi la primera flor que se abrió en el año». El tema central de la peripecia por adorno o gesto - el de ofrecer o el de colocarle la flor - expresado mediante la optación con que se inicia el último terceto: "Lógrese en tu cabello, respetada", se ve precedido por una digresión temática marginal sobre la ponderación de la hermosura fugaz de la rosa en las tres primeras estrofas de la composición.

No obstante los casos de estructuras textuales relativamente simples, como el del soneto anterior, no son ni mucho menos lo más frecuente. 
Ya hemos advertido (2.0) que en muchos sonetos la organización temática del texto se constituye como una verdadera red sintáctica, absolutamente análoga a la que organiza la enunciación de período sintáctico compuesto. Veamos algún ejemplo. Para comenzar, el soneto de confidente que titula «Encomienda su llanto a Guadalquivir en su nacimiento, para que le lleve a Lisi, donde va muy crecidon:

Aquí, en las altas sierras de Segura, que se mezclan zafir con el del cielo, en cuna naces, líquida, de yelo, y bien con majestad en tanta altura.

Naces, Guadalquivir, de fuente pura, donde de tus cristales, leve el vuelo, se retuerce corriente por el suelo, después que se arrojó por peña dura.

Aqui el primer tributo en llanto envío a tus raudales, porque a Lisi hermosa mis lágrimas la ofrezcas con que creces;

mas temo, como a verla llegas rio, que olvide tu corriente poderosa el aumento que arroyo me agradeces.

El esquema del texto en los términos de representación sintáctica a que antes nos referiamos, sería el siguiente:

1, Expansión temática actancial:

1 Encomienda temática central:

$1_{2}$ Expansión temática actancial:

2 Correlación temática secundaria de la predicación

2 Expansión temática actancial:

Correlación de la predicación 2
Guadalquivir naces arroyo aquí (Expansion-Descripción topográfico-poética)

Ofrece tú mis lágrimas a Lisi

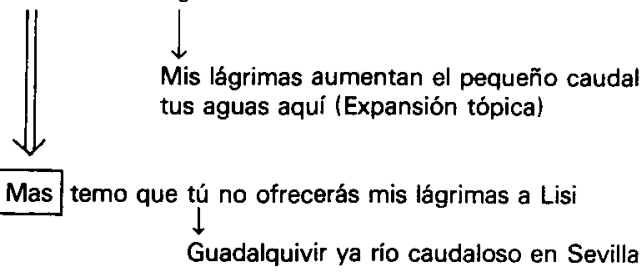<smiles>C[CH]C</smiles>

Olvidarás el pequeño aporte de mis lágrimas 
Esquemas como el precedente podrian explicar perfectamente la constitución temático-textual de la mayor parte de los sonetos del Canto a Lisi, tomado en este capítulo como muestra convencionalmente restringida por razones de economía expositiva. Debemos añadir, con todo, que resulta obvio que no siempre quedan explícitas en el desarrollo terminal de la superficie del texto las relaciones entre enunciados temáticos constitutivos del mismo, de la misma manera que en el análisis sentencial de períodos complejos y sobre todo en el de cláusulas sintácticas, resultan a menudo simplemente implícitas las relaciones lógico-sintácticas entre los componentes. Un ejemplo ilustrativo de un discurso de complejidad normal, donde se registran abundantes casos de correlaciones temáticas no explícitas puede ofrecerlo el caso del titulado: "Que como su amor no fue sólo de las partes exteriores, que son mortales, ansi también no lo será su amor» (11). A continuación proponemos el esquema correspondiente:

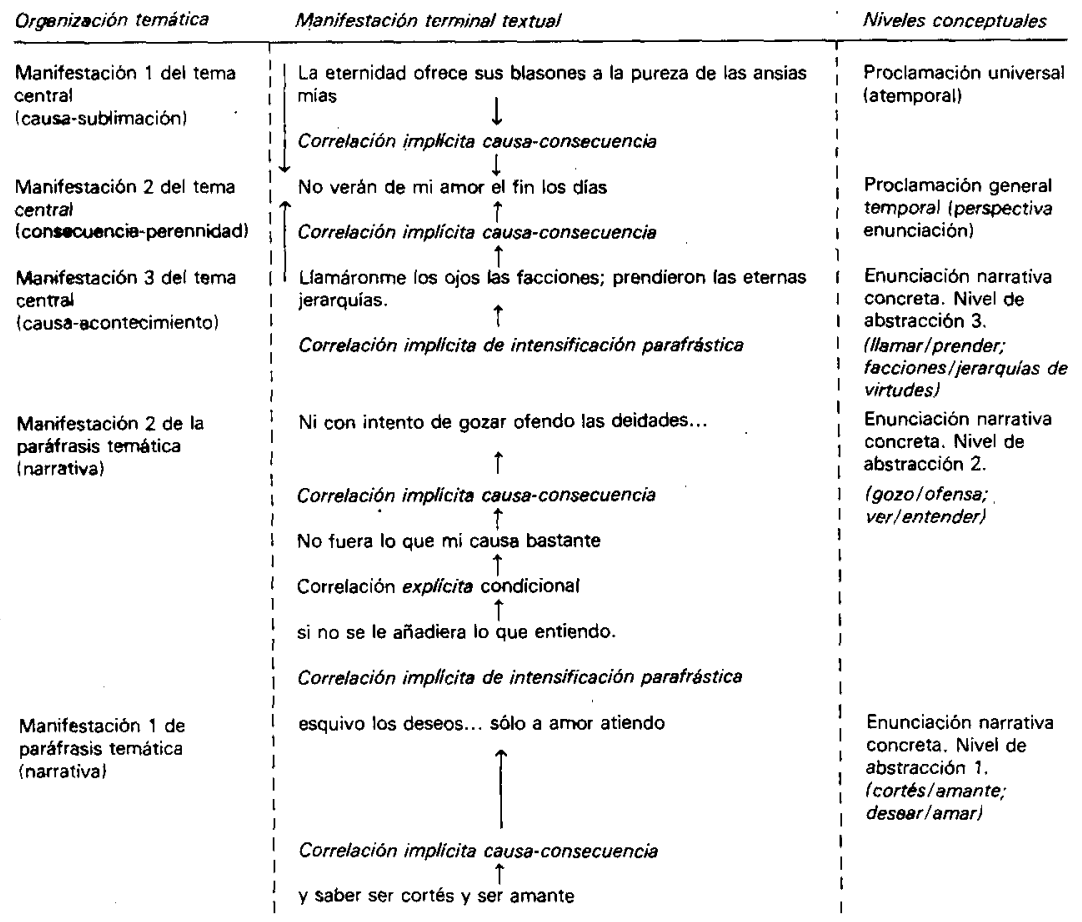

Adviértase que la estructura de construcción macrotextual más frecuentada por Quevedo, la que he denominado (García Berrio, 1980) de 
isodistribución múltiple, a la que corresponde también el ejemplo que he esquematizado, favorece el tipo de correlaciones implícitas que acabamos de señalar, a través de la sustantividad y autonomía sintácticotemática sin transgresiones de cada una de las cuatro unidades-estrofas de la composición y la ausencia de conectores explícitos. Por lo demás, destaca en el conjunto de textos quevedescos en esta muestra del Canto a Lisi, como ya hemos señalado, el respeto sin esfuerzos al unitematismo programático del soneto que el autor sabe explicitar a través de los más variados procedimientos, como organización del razonamiento a su tema-conciusión final, que representaría el soneto en que "Con la comparación de dos toros celosos, pide a Lisi no se admire del sentimiento de sus celos», cuya estructura discursiva esquematizariamos:

1. Ponderación positiva del símil: ¿Ves la lucha de los toros encelados?

2. Ponderación negación del símil 2: ¿No ves su porfía?

3. Consecuencia: Ves, ¿por qué te admira su ira?

4. Condición subordinada a 3: si lo ves

5. Intensificación parafrástica: los toros son capaces de sus ansias

6. Adversación de 5: ¿y no permites mi llanto?

7. Condición subordinada a 6: cuando a mi rival miras.

En otros tipos textuales la organización de la progresión temática hacia la formulación superficial del tema básico se organiza en torno a la sucesividad lógico-temporal de los constituyentes del enunciado, como

(11) Véase el texto del soneto mencionado:

Que vos me permitáis sólo pretendo, y saber ser cortés $y$ ser amante; esquivo los deseos, y constante, sin pretensión, a sólo amar atiendo.

Ni con intento de gozar ofendo las deidades del garbo $y$ del semblante; no fuera lo que vi causa bastante, si no se le añadiera lo que entiendo.

Llamáronme los ojos las faciones; prendiéronlos eternas jerarquías de virtudes y heroicas perfecciones.

No verán de mi amor el fin los dias: la eternidad ofrece sus blasones a la pureza de las ansias mías. 
en el soneto titulado «Rendimiento de amante desterrado que se deja en poder de su tristeza» (12). La sucesión temporal se ciñe en él a cada momento de la representación estrófica. Así en el primer cuarteto se describe la situación actual de sufrimiento, vinculada a la conocida imagen del llanto-río. En el segundo se presenta la optación futura de muerte liberadora; con el primer terceto se introduce la situación tópica postmortem como «espíritu desnudo», mientras que el último terceto transfiere a valor de sentencia atemporal el proceso antes descrito, concluyendo incluso con la sintesis explícita del tema central de la glorificación como sentencia epitáfica - "Ya fue gloria de Amor hacerme guerra». Y a esta misma estructura se ajusta el procesualismo local de textos bajo la organización procesual-local, como los sonetos con el símil temático de itinerario, un característico ejemplo de los cuales, también dentro de la muestra aquí delimitada, podría ser el que comienza "Cargado voy de mí: veo delante», con el significativo título «Exhorta a los que amaren, que no sigan los pasos donde ha hecho su viaje».

2.4. El caso de los temas unidos con función de interdependencia en el interior del texto presenta lógicamente problemas mucho más acusados a la hora de las decisiones de jerarquización. Obviamente se trata de dos constantes coimplicadas, en las que la recíproca necesidad lógica de los diferentes temás es absoluta. En tales casos, si la determinación constituía un caso de subordinación lógica subrayada por conectores explícitos, es decir que la jerarquización se establecía sobre el doble sustento lógico y formal, ahora en la interdependencia la jerarquización, en

(12) Véase el aludido texto, Quevedo p. 22, $n^{\circ}$ 122:

Éstas son y serán ya las postreras lágrimas que, con fuerza de voz viva, perderé en esta fuente fugitiva, que las lleva a la sed de tantas fieras.

¡Dichoso yo que, en playas extranjeras, siendo alimento a pena tan esquiva, halle muerte piadosa, que derriba tanto vano edificio de quimeras!

Espíritu desnudo, puro amante, sobre el sol arderé, y el cuerpo frío se acordará de Amor en polvo y tierra.

Yo me seré epitafio al caminante, pues le dirá, sin vida, el rostro mío: "Ya fue gloria de Amor hacerme guerra". 
sentido estricto, se establecerá en función de un orden estrictamente formal inherente al texto; es decir, será sólo la naturaleza y orden del enunciado lo que determinará el sentido de la jerarquización.

Algunos de los temas censados por nosotros en la tipología implican constitutivamente relaciones internas de determinación. Sobre todo descubrimos esta situación en ciertas clases de textos de estructura tópica y gran notoriedad histórico-literaria etiquetados por mi, en virtud de tales circunstancias como si fuesen unitemáticos. Pensemos, por ejemplo, en el tipo de carpe-diem. En realidad, bajo una sola denominación temática se engloban inadecuadamente al menos tres temas distintos, que se corresponden con las tres parcelas de desenvolvimiento lógico de la acción: encarecimiento de la belleza actual / incitación epicúrea / admonición sobre la degradación futura. El encaje de las piezas del razonamiento se ajusta a un esquema temporal-causal muy evidente, que podriamos sintetizar de varios modos, pero quizás el más sencillo sea el siguiente para la realización estándar del tema:

\section{Disfruta de tu belleza --- antes que el tiempo la marchite --- porque el tiempo la marchitará}

De acuerdo, pues, con esta consideración el del «carpe diem» no es un tema en el sentido en que lo hemos definido y establecido nosotros, sino un conglomerado textual temático, o si se quiere un architema.

Al mismo tipo de los architemas o temas conglomerados con relación implícita de interdependencia, pertenece la glorificación en sus distintas modalidades. Con independencia, como en el "carpe diem», de los temas secundarios adheridos en determinación o constelación, la definición semántica de la glorificación implica obligadamente la predicación temática: de un lado «el poeta sufre gustoso los rigores de su enfermedad», y de otro «la belleza de la dama»/la "gentileza» singular del sentimiento amoroso justifican la relación amorosa. Entre ambos vuelve a establecerse la misma vinculación de interdependencia causal que descubríamos antes en el caso del carpe diem. Véase el funcionamiento integral interdependiente de la predicación textual en el siguiente soneto de Quevedo, perteneciente a la clase glorificación con superación de la queja:

Si hermoso el lazo fue, si dulce el cebo, fue tirana la red, la prisión dura; esto a mi suerte, aquello a tu hermosura, preso, y amante, Lísida, les debo. 
El lazo me invidiaron Jove y Febo;

Amor, del cebo, invidia la dulzura;

la red y la prisión mi desventura

crece, yo las adoro y las renuevo.

Yo las adoro y nunca las padezco;

$y$ en la red $y$ prisiones amarrado,

lo que viví sin ellas aborrezco.

Igualmente gozoso y abrasado

la llama adoro y el incendio crezco;

¡tan alto precio tiene mi cuidado!

La ponderación de los aspectos positivos y negativos vinculados a la hermosura se va realizando, de modo más o menos simultáneo, a lo largo de toda la composición y desde el primer verso. Sin embargo podemos convenir que la glorificación superadora, la parte positiva, se construye regularmente en los tercetos, posición habitual de la regla métrica, que hace que, en efecto, la cabeza de este architema textual coincida con la posición habitual del determinante temático del texto.

Un tercer tipo de textos por definición architemáticos con relación interdependiente causal son los que expresan la circunstancia temática de las quejas por engaño-desengaño, en los que no resulta difícil imaginar, dentro de su relativa riqueza de variantes de realización, la ordenación de la estructura de la causa-consecuencia, del tipo:

a) me quejo / porque / la dama, el Amor o yo mismo me engaña, que a su vez supone la estructura causal secundaria

b) me ilusiono engañosamente / porque / la dama, el Amor o yo mismo me dio fundamento

Veamos la articulación concreta del caso general en algún texto concreto como el siguiente de Herrera:

Dessea descansar de tanta pena, conociendo ya tarde'l desengaño, mi alma, hecha a su dolor estraño; i d'el perdido tiempo se condena.

Vê su triste esperança d'ansias llena; poco bien; mucho mal; perpetuo daño; $i$ las glorias devidas, cierto engaño; que'el su dulce tirano al fin ordena. 
Siente sus fuerças flacas i sin brio, i su desseo vano i peligroso;

i medrosa levanta apena el buelo.

Amor, porque no cresca en ella el frio,

el fuego aviva, do arde; i sin reposo

busca i gime, hallando luz d'el cielo.

cuyo esquema hemos resuelto bajo la siguiente síntesis-fórmula de ordenación:

el Amor anima el fuego / porque / yo trato de soltarme,

estableciendo, como ya hemos indicado, el tema directriz de la interdependencia en la frase independiente, reforzada aquí una vez más por la regla métrica y la estructura de la construcción textual.

No obstante, puede decirse que en todos los casos de textos architemáticos como los anteriores, lo que se privilegia es precisamente la unidad interdependiente de los componentes temáticos del texto, de tal manera que las cuestiones de orden relativo entre los mencionados componentes vienen a resultar irrelevantes, dado que en esos casos las unidades semánticas componentes no son tanto temas como constituyentes del architema. En todos los demás casos no sucede de esta manera. La disposición de los temas, y sobre todo la forma en la que se expresa la relación interdependiente resulta decisiva a la hora de establecer la jerarquía temática en el interior del texto. En los textos no architemáticos de construcción interdependiente, en los que se asocian temas libres bajo un tipo de función interdeterminada, resulta obligado tener en cuenta la disposición de los temas dentro de la función para establecer automáticamente la condición de fundamental y secundario, siguiendo los mismos criterios adoptados usualmente en el análisis de la interdependencia oracional. Asi, por ejemplo, en las relaciones causalconsecutivas, la atribución de frase principal/determinante se realiza sobre la frase simple que incorpora el elemento no marcado de la relación; por ejemplo decimos que en la frase causal

$$
\text { Juan lo hizo / porque / dejó aquí su tarjeta, }
$$

la proposición principal, que nosotros prefeririamos denominar directriz o independiente la expresa "Juan lo hizo", elemento no marcado de la relación causal; ya que la expresión de la causa, en virtud de la cual deducimos la responsabilidad de Juan en la acción, es que «dejara su tarjeta». Relación aún más inmediata en expresiones directas de causa real, como "Juan se marchó porque le echaron», u otras semejantes. 
El criterio antes reseñado permite resolver, por sí mismo y de modo inmediato, numerosos casos de duda que pueden ofrecerse en la jerarquización temática de textos. Veamos el siguiente ejemplo de Fernando de Herrera:

Yo vi, a mi dulce Lumbre qu'esparzia sus crespas ondas d'oro al manso viento, i con tierno i suäve movimiento, mi duro coraçon enternecia;

Mi rustiqueza, $i$ torpe rebeldia, perdio, vencida, el ostinado intento; $i$ en blando i regalado sentimiento, trocò mi alma l'aspereza mia.

Nunca me vi mas preso ni rendido, i nunca vi en mi Luz mayor dureza; ni mas rezio desden; ni largo olvido.

A termino tan grave, $i$ estrecheza Casas, mi triste suerte m'a traido; que temo de mi Lumbre la belleza.

El componente de ponderación positiva prima en la estructura del texto, disponiéndola para cualquiera de las formas del canto, de retrato o más bien de glorificación superadora de la queja. Sin embargo, basta con señalar la presencia de la relación. causal básica. "Temo la belleza de mi dama / porque / me produce estrechez y desazón", para establecer automáticamente el criterio que sanciona las quejas de la dama como tema central de la composición. Lo que, por lo demás, produce la usual convergencia de criterios, aquí por ejemplo con el lógico y el métrico, en los casos de sonetos bien construidos.

Un ejemplo quizás todavía más complejo, que permite ilustrar con mayor interés sin duda la organización jerárquica de los varios temas que abundan en un texto; mediante la éxplicitación de la regla causal en el caso de temas interdependientes, lo ofrece el siguiente soneto de Fernando de Herrera:

La Luz serena mia; el oro ardiente, en mil cercos luzientes dividido; $i$ en dulce nieve i purpura teñido, Casa, el color suäve de la frente; 
Cánto, i, como el ingrato Amor consiente ciego en su esplendor bello, estoi herido, i oscuresco sus glorias, ofendido de tanto bien con lira i voz doliente.

Oso, i aunqu'el desseo me levante, el peso es grande, i culpa mi osadia; quien amára el peligro de mi pena.

Mas el cielo cansò al sobervio Atlante; i no es mayor su empresa que la mía, pero si el vano error, que me condena.

Advertimos, además que, como veremos, la regla métrica en este caso no subraya directamente el tema en su manifestación lineal terminal propiamente dicha, sino que ofrece excepcionalmente el subrayado metalingüístico de una reiteración parafrástica. Para nosotros el «vano error» que implica temáticamente el caso de engaño-desengaño encuentra el fundamento de su acuñación explícita textual bastante antes en el desarrollo del texto, concretamente en los versos 7-8, donde el poeta manifiesta que "oscurece las glorias" (desengaño) de las hermosuras que "canta» (base del engaño). Estableciendo la paráfrasis de estructuración interdependiente causal de los cuartetos, tenemos satisfactoriamente explicitado, a mi juicio, el esquema funcional temático del texto.

Yo oscurezco doliente las glorias $>$ porque estoy herido $>$ porque el Amor me ciega =porque las glorias de la dama son cegadoras.

En cuanto al resto de la composición en los tercetos, nada añade a la problemática de los temas, pues se trata de una paráfrasis directa de la situación anterior, en el primero, y otra paráfrasis con ponderación metafórica en el segundo.

2.5. Ya hemos indicado antes que la tercera modalidad de funcionalismo lingüístico, la constelación, resulta inviable en el caso del soneto bien construido, en virtud de las convenciones de definición que establecen su estructura unitemática y sus dimensiones textuales específicas. La constelación al exigir la condición de variables, en distribución por tanto autónoma, para cada uno de los componentes temáti$c o s$, implica de una parte una extensión textual que el soneto no tiene, y de otra que, pensando en el texto como unidad, la constelación sólo es posible como función no últimamente profunda, sino subordinada a una 
predicación unitaria, concebida en términos del mismo nivel de concreción temática o en otros más abstractos.

Asi pues sólo el caso del soneto fallido o defectuoso podría deparar ejemplos de constelación de temas centrales, es decir de pluritematismo principal. Tales ejemplos no existen en nuestra muestra, dada la altísima indole artística de los escritores censados, habida cuenta además, de que el defecto de pluritematismo era de los de mayor cuerpo. Sólo en el caso de un tipo de sonetos por definición raros y defectuosos podríamos aducir ejeınplos de construcción próximos - ni siquiera puros - a la funcionalidad constelativa. Se trata de esa especie de textos de puro virtuosismo o ingeniosidad no infrecuentes en el Siglo de Oro, tales como los sonetos en varias lenguas, los que utilizan sólo palabras comenzadas por una vocal determinada, etc., etc. Un ejemplo relativamente válido podría ofrecerlo un texto de Fernando de Herrera - o quizás, según otras hipótesis, del pintor Pacheco, en mayor o menor grado, ya que pertenece a la obra póstuma del poeta sevillano Versos (Libro II, soneto 17). El artificio en él consiste en mantener en posición final de verso, construyendo rima, las mismas palabras, «ielo» $y$ "fuego» en los cuartetos y «muerte» y "vida» en los tercetos (13). Ya el mero enunciado de las rimas señala los dos cuerpos temáticos en los que aparece dividido este texto: símiles temáticos de contraste, y sufrimiento muerte, respectivamente. Si bien ambos aparecen notablemente deformados por el pie forzado del artificio al que se sacrifica todo proyecto de semantismo sensato. En tal sentido el tema común que podría

(13) Corrobórense nuestras afirmaciones con el referido texto:

Ardo, Amor, i no enciende'l fuego al ielo, $i$ con el ielo no entorpesco al fuego. contrasta el muerto ielø al vivo fuego. todo soi vivo fuego i muerto ielo.

No tiene'l frio polo tanto ielo, ni ocupa el cerco eterio tanto fuego tan igual es mi pena; que ni el fuego $m$ 'ofende mas, ni menos daña el ielo.

Muero, i vivo, en la vida, i en la muerte, i la muerte no acaba, ni la vida; porque la vida crece con la muerte.

Tu, que puedes hazer la muerte vida: porque me tienes viuo en esta muerte? porque me tienes muerto en esta vida? 
dominar, antes tendría que ver con antítesis o contrastes, pero sin poder especificar la dependencia de una clase temática común, pues no la tiene.

En la primera mención de esta problemática de la constelación aludíamos al famoso soneto de Quevedo "Amor constante más allá de la muerte», como ejemplo que, sin presentar en último término este tipo de construcción, podia aproximarse a ella en un primer grado de acercamiento. En efecto el sistema de paráfrasis de la primera enunciación, generalmente expuesta en los cuartetos, mediante un cuerpo en otro plano en los tercetos, presenta el riesgo de que, cuando se debilitan las marcas de afinidad internas que deben contener cada una de las partes en proporción o se desajustan por torpeza los conectores de determinación, crece el efecto de autonomía de las partes, lo que puede precipitar la imagen de dos temas centrales constelados. Ciertos textos de Quevedo, realmente, se aproximan a ese supuesto, en mucho mayor grado que el antes mencionado soneto magistral; singularmente determinados sonetos con fuerte corporeización del símil y mucho más débil proporción entre los principios comparados, entre los que propondríamos como ejemplo el que se titula «Dice que como el Niño guarda su origen, encubre también el de su amor la causa, y crece ansí también su llanto con el fuego que le abrasa». La intransgredida autonomía de los dos elementos de la comparación en los dos dominios básicos del texto, e incluso ciertos datos de construcción tales como la doble invocación y el tono apelativo subsiguiente, al Nilo y a Lisi (14), configuran una ima-

(14) Véase el texto aludido:

Dichoso tú, que naces sin testigo

y de progenitores ignorados,

¡oh Nilo!, y nube y río, al campo y prados, ya fertilizas troncos y ya trigo.

El humor que, sediento $y$ enemigo, bebe el rabioso Can a los sagrados ríos, le añade pródigo a tus vados, siendo Acuario el Léon para contigo.

No de otra suerte, Lisis, acontece a las undosas urnas de mis ojos, cuyo ignorado origen se enmudece.

Pues cuanto el Sirio de tus lazos rojos arde en bochornos de oro crespo, crece más su raudal, tu yelo y mis enojos. 
gen muy marcada de bitematismo independiente, que queda sin embargo descartado tras la corroboración de la precisa correspondencia y paralelismos entre los elementos semánticos constitutivos y la modalidad constructiva de las dos mitades del símil.

3.1. Hasta ahora nos hemos planteado la cuestión de la determinación del tema en el texto sólo en uno de sus dos aspectos sustanciales, el de la localización de aquella parcela del enunciado textual que presenta dominancia generativa sobre las restantes. Pero en la operación de determinación temática hemos de considerar también un segundo aspecto, que es el de la conceptualización del tema. Es decir, una vez localizado el fragmento de enunciado textual que obedece a esa unidad de cohesión sintáctico-semántica y de unidad comunicativa que hemos definido (2.0) como tema, la cuestión se plantea en términos de acotarlo conceptualmente como tal. Esta nueva operación implica básicamente dos aspectos:

a) deducción y sumarización de la representación semántica adecuada

b) etiquetado de la representación léxica impuesta

La deducción de la representación semántica es una operación sustancialmente de síntesis o sumarización (van Dijk, Kintsch, 1978), en virtud de la cual el analizador, y a veces incluso - como veremos- el propio poeta, construye un enunciado sintético con capacidad de funcionar como predicación de base de la extensión del enunciado textual que está probando como tema. La adecuación de este proceso se mide mediante capacidad de expansión de la fórmula de predicación bajo tentativa a la totalidad del texto cuya representación semántica trata de asumir, dicha expansión se operará mediante transformaciones generalizadas desde los elementos de la predicación básica.

Respecto a la sumarización del enunciado textual en el tema o temas que lo componen, primera operación de la conceptualización del tema, no exige el texto del soneto de estrategias específicas, al menos respecto de las requeridas por otros tipos de enunciados poéticos de la misma época. La sumarización supone la intuición previa dé la localización y subsiguiente discriminación de los temas componentes del texto. Por otra parte supone también la actividąd de los presupuestos de cultura histórico-literarios. Claro está que en términos operativos de la práctica, lo que se registra es la simultaneidad de todas las anteriores operaciones 
y presupuestos. En el estado original intuitivo del que parte el análisis sobre la estructura temática de un texto, las intuiciones de conceptualización llegan casi siempre antes que las de delimitación. Con mucha frecuencia además, como veremos en algunos ejemplos concretos, los casos más dudosos de jerarquización y aun de conceptualización temática se registran en el interior de enunciados textuales complejos en los que se funden, con límites no siempre absolutamente precisos, temas muy próximos, deducidos de una clase temática única. Sólo progresando en el análisis, llega un momento en que una determinada operación estabilizada ya en una conclusión segura, generalmente la localización y delimitación de temas, precede realmente a otra, comúnmente la sumarización conceptual del tema, todavía en fase de tentativa.

Las reglas de sumarización del tema, o mejor dicho del fragmento de desarrollo textual bajo la dominancia del tema, tendrán seguramente el mismo estatuto en el caso de nuestros textos que los que se pueden establecer para tipos homólogos de discurso; y no es objeto de este trabajo ofrecer un tratamiento pormenorizado de los mismos, ni mucho menos la tentativa de formalización exigible desde tal propósito, si se pretende desarrollarlo monográficamente, caso que, por la índole mucho más general de nuestros problemas, no puede ser el nuestro. Aquí nos ocuparemos sólo de explicitar determinados mecanismos de conceptualización temática, y sobre todo de ejemplificar ciertos tipos de decisiones dudosas. Comenzando por las reglas generales, resulta obvio que, de acuerdo con nuestra definición de los componentes temáticos (2.1), tal operación deberá integrar básicamente las decisiones en torno a los factores constitutivos del género y la clase temática con los estrictamente constitutivos del tema, ya que la cuestión de la modalidad expresiva no presenta relieve alguno en la estructura básica de la sumarización y conceptualización textual. Sin embargo los problemas para la sumarización de ambos componentes son muy distintos, los que atañen a los componentes de la clase temática se deducen automáticamente de su incidencia explícita en el cuerpo del texto. Ilustración de la que acabamos de decir que puede constituirla, por ejemplo, la necesidad de crear todo un apartado tipológico en las quejas para el $A m o r$, un eufemismo en realidad de la dama - para evitarle agresiones descortesesy en otros supuestos del poeta mismo - comúnmente en los casos vinculables a ceguera y desengaño. La presencia explícita en el texto de este actor objeto, y no de cualquiera de los otros, obliga a la correspondiente inserción del mismo en la definición y conceptualización del tema. Un ejemplo concreto de signo contrario puede ofrecerlo el siguiente soneto de Lope de Vega: 
Rompa con dulces números el canto de alguno al son de la confusa guerra, entre el rumor del escuadrón que cierra el silencio a la voz y a Juno el manto.

Cante las armas de Fernando santo, o el de Aragón en la nevada sierra, del duque Albano en la flamenca tierra, $u$ del hijo de Carlos en Lepanto.

Otro cante a Cortés, que por España levanta las banderas por el polo que cuando nace el sol de sombras baña;

que yo, Lucinda, si me ayuda Apolo, aunque vencerme tú fue humilde hazaña, nací para cantar tu nombre solo.

El contenido de este soneto y su estructura presentan en la mayoría de su desarrollo la imagen de una temática bien distinta a la de su real definición, que es la de la modalidad temática canto-proclamación $\left(4_{1}\right.$ $a_{1}$ ): incluso se podría pensar en un soneto literario o mejor conmemorativo en su modalidad bélica. Pero, descartadas ya por lejanas tales hipótesis, se podría pensar lícitamente sin embargo en un tipo de temas de confidente, muy cultivado por Fernando de Herrera, consistente en la ponderación como más útil y gloriosa de la actividad militar o literaria del confidente apelado, para contrastarla, con saldo positivo o negativo, con la imposibilidad propia de atender a cualquier tipo de actividad o de ejercicio literario que no sea la celebración de las venturas y desventuras del propio amor. A este tipo temático, muy bien perfilado sobre todo en Herrera, le dedicamos incluso una terminal tipológica dentro de la clase temática del confidente $\left(5_{2} d_{1}\right)$, en nuestras primeras versiones de la tipología temática (García Berrio, 1977, 1978), que en la'reducción económica de esta tipología ha sido asumida con otras variedades en la esquematización actual (García Berrio, 1980, 1980a, 1981). Sin embargo la ausencia de apelación a los personajes mejor ocupados, requisito a través del cual se posibilita la conversión de los mismos en actantes, confidentes, de la predicación temática de base imposibilita incluir el enunciado del texto en la clase temática del confidente (15).

Más aguda y difícil, por cuanto no se refiere, como en el caso precedente, a un sistema cerrado y explícito de requisitos y condiciones, se 
presenta la problemática de la sumarización de la representación semántica del tema en lo que respecta al componente de inserción semántica en el funtor de la predicación, complementario de la clase temática, al que hemos considerado como segundo factor de la definición del tema. Aquí cuenta todo lo que hemos ponderado previamente sobre la complementaridad de servicios del análisis y las presuposiciones, así como las cuestiones sobre la simultaneidad o sucesividad en el orden de operaciones y presuposiciones. En términos generales la mayor parte de los textos resultan totalmente aproblemáticos; en especial una vez que ya se cuenta con la suficiente experiencia en el dominio del marco sistemático de la tipología. Aunque lo anterior pueda parecer una aseveración general u obvia, creemos que no es así. Considérese al respecto la seguridad y comodidad automática con la que se etiquetan sonetos como los de "carpe diem», o los mucho más raros de "celos». Seguridad que viene en gran medida del alto grado de estabilización en la conciencia cultural literaria de los contenidos temáticos indicados; lo que por otra parte lleva aparejado el frecuente error de atribuir, por una presencia secundaria en ellos, tales temas más conspicuos a textos con tema central diferente. El problema es que frente al conjunto real de temas literarios incorporados al sistema cultural de la lírica amoroso-cortés, el número de los tópicos históricamente notorios es ciertamente insignificante; en constataciones como éstas fundamos el valor y la necesidad de tipologías como las nuestras. A medida que el número de los temas va apareciendo más concretado y más orgánicamente justificado en términos del sistema funcional, crece proporcionalmente la facilidad de sancionar con inmediatez, comodidad y acierto semejantes al de los pocos temas históricamente notorios, el resto de la temática.

En la práctica, el perfil de la representación semántica de los temas, tal y como lo reflejan las terminales de nuestra esquematización tipológica, es la consecuencia de las mismas estrategias de constitución del sistema tipológico que hemos ido operando. De manera intuitiva se nos ofreció en principio el sistema, como es lógico, en sus grandes líneas de constitución de las distintas clases temáticas, de predicados y actanciales; no en balde las razones de decisión en estos casos constituyen

(15) Más exactamente del canto con confidente, ya que el confidente como los circunstantes son desarrollos facultativos - positivo/grado cero- de las tres clases temáticas fundamentales - canto, queja y sufrimiento- determinados a partir de los funtores de predicación. De estas cuestiones lingüísticas que afectan al confidente, como de las que se refieren al estatuto lógico-lingüístico de los demás componentes de la predicación temática nos ocupamos en detalle en nuestro trabajo Actancia, circunstancia y predicación textual. 
un inventario cerrado y explícito de combinaciones posibles. Pero, curiosamente, los distintos temas adheridos al predicado de la clase, que constituyen los racimos temáticos terminales, ofrecen un sorprendente grado de homogeneidad y de limitación. Piénsese en casos tan sorprendentes, para una primera apariencia, como el del confidente-río, o la asociación temática de la antítesis a la definición del Amor y muchos otros. Prodigio por lo demás fácilmente explicable, y no ciertamente por efecto de nuestra presión de analistas tentados por vicios de simplificación y esquematismo. Simplificación y esquematismo son sobre todo características razonablemente constitutivas de los sistemas culturales altamente topificados, como es el sistema de la lírica clásica; y no sólo vicios de analistas. El propio sistema nos ofrece elocuentes testimonios explícitos de simplificación en casos tan notorios como el reducidísimo inventario de partes corporales constitutivas del retrato, o la frecuentación de determinados símiles insistentes, algunos bien individuados por la historia literaria como los contrastes cromáticos y térmicos; pero otros no ciertamente tal, aunque su grado de frecuentación no resultara ni mucho menos bajo, como la asociación llanto/río, o el símil de la mirada del águila al sol/con el atrevimiento a contemplar la dama, o el muy análogo de la salamandra, etc., etc.

Constatada esta importante experiencia que caracteriza el sistema cultural tópico de la lírica clásica, he de añadir una segunda, ésta seguramente más participada, y es la capacidad de autoorganización de los materiales de la realidad. Tal confianza, que he ido adquiriendo «a posteriori» según ha avanzado el desarrollo de mis trabajos tipológicos, resulta un principio de seguridad imprescindible en la construcción tipológica. En el conocido consejo de la metodología de la investigación filológica de que un número representativo de fichas (datos) constituye una teoria, que descubre en sí misma las líneas de su constitución a través de esa especie de mágicas afinidades con que las fichas (datos) se organizan «por sí mismas», hay quizás mucho a imputar al filtro del punto de vista del analista; pero no menos tampoco a atribuir a la naturaleza objetiva misma de los fenómenos culturales, productos humanos en suma, afectados por tanto de todas las limitaciones y peculiaridades de nuestra estructura mental. Y si el primer factor no debe dejar de preocuparnos a los precavidos, la confianza en el segundo no debemos dejar que nos la escamoteen los escépticos.

Los pasos sucesivos en el establecimiento del sumario de la representación semántica del tema, desde la perspectiva operativa de la confección del modelo tipológico, que hemos adoptado aquí, se concentran en: 
a) la descomposición en sus rasgos semánticos mínimos - «semas»- componentes del conjunto "semantemático» de la representación semántica textual y en el recuento de los mismos;

b) establecimiento de una comunidad económica de rasgos - «semas»-comunes y consiguiente desestimación de "semas» accesorios no comunes, en función del mencionado criterio de economía.

Quizás pueda extrañar que invoque frecuentemente en mis trabajos el principio de economía, en su doble aspecto de economía de las estrategias y economía del algoritmo. La ausencia de trabajos tipológicos de verdadero empeño en las recientes épocas doradas de las teorías lingüisticas inductivas y de modelos hipotéticos inadecuadamente verificados puede precipitar una errónea sospecha de «impureza acientífica» sobre un tipo de trabajo que afecta tan frecuentemente a un criterio por definición «aproximante». Sin embargo tal tipo de escrúpulos desconoce la esencia, por definición, de la actividad tipológica. Toda "clase terminal» en cualquier tipología es fundamentalmente el fruto de una convención basada en el doble principio de economia de estrategias y algoritmo. La razón es inmediata, en último término la única clase terminal realmente auténtica es el individuo. Nuestra descomposición tipológica del «corpus» de la poesía amorosa puede proceder, como es fácilmente comprensible, en la línea de descomposiciones progresivas de sus componentes terminales, hasta alcanzar tantas terminales como individuos muestreados; pues cada poema es único salvo el caso del plagio literal en su constitución macro- y microcomponencial, y aun dentro de.esta última se pueden considerar niveles de afinidad para los textos escritos que alcanzan no sólo a las microestructuras sintácticas, sino incluso a los más elementales constituyentes léxicos del texto. $E$ incluso, si consideramos el soneto como texto de la lengua oral, cualquier modificación tonal o fonética de su ejecución oral obligaría en puridad a abrir una nueva terminal-variante tipológica; como en el mismo sentido, pero con mucha mayor justificación, puede hacerse con la ejecución de las partituras musicales. Creemos obvio, por todo lo anterior, que las razones de economía se imponen en el trabajo tipológico; $y$ aun añadiríamos que llegar a concretar exactamente la adecuada rentabilidad de tal economía tipológica constituye la principal exigencia de cientificidad en este tipo de trabajos.

Los criterios básicos que regulan el nivel óptimo de economicidad en la anterior determinación b) vienen establecidos, a su vez, por:

a) la proporción en el número de rasgos - "ssemas»-comunes selec- 
cionados para el establecimiento de la terminal temática, en relación con el número seleccionado en las demás terminales del esquema,

b) la proporción en el número de individuos - sonetos - comprendjdos en cada terminal, en relación con el número incluido en las demás terminales del esquema.

Respecto a la primera cuestión se trata de salvar las desproporciones de comprensión lógica entre los diferentes temas terminales. Se entiende, sin embargo, que algunos temas son, por definición, más concretos en cuanto a las notas constitutivas de su definición lógico-semántica que otros; así, sumarios temáticos como los incluidos bajo las denominaciones terminales de «proclamación $\left(4_{1} a_{1}\right)$, o «quejas directas» de la dama $\left(4_{1} b_{1}\right)$, «del Amor» $\left(4_{1} b_{6}\right)$, o del poeta mismo $\left(4_{1} b_{5}\right)$, alcanzan un inventario estructural temático mucho más reducido de rasgos que cualquiera de las demás terminales dominadas por la terminal común de las respectivas clases temáticas, pues todas éstas suponen la definición básica del criterio generador correspondiente, más la nota o notas diferenciales. Obviamente la razón de ser en tales definiciones de mínima comprensión es que son las adecuadas para definir un número muy abundante de textos que presenta tales características temáticotextuales.

En estrecha correspondencia con el criterio anterior se mueve el segundo b), que afecta a la extensión lógica de la definición. Evidentemente el número de textos incorporados a cada una de las terminales debe ser relativamente representativo, lo que no quiere decir necesariamente homogéneo. La desproporción numérica de la muestra acogida en cada terminal debe reflejar la frecuencia relativa de cultivo del tópico en cuestión respecto a los demás, antes que a ninguna exigencia de esquematismo apriorístico. No obstante, el criterio de economía aconsejaría en relación con este punto el establecimiento de una regla de mínimos, según la cual el mantenimiento de terminales tipológicas para acoger a textos únicos y por tanto excepcionales - no necesariamente en sentido cualitativo- no resulta aconsejable. Si el rasgo temático seleccionante fuera incuestionablemente central, resulta aconsejable destacar dicho texto en una lista de excepciones del sistema tópico; en caso de duda, lo aconsejable es incluirlo en la terminal del tema no excepcional. Sin embargo debemos confesar aqui, como lo haciamos en las primeras formulaciones de la teoria tipológica hechas sobre una muestra más restringida que la actual (García Berrio, 1978: 28) que estamos haciendo una previsión puramente teórica ya que no se nos ha presentado aún el caso de textos con temas de esta naturaleza. 
Una vez más hemos de invocar como justificación de este nuevo fenómeno restrictivo la congruencia interna inherente a los sistemas culturales tópicos. En la muestra que hemos alcanzado, los muy contados sonetos irreducibles al sistema general, lo son más bien por incumplimiento de las condiciones predicativo-actanciales que regulan la clase temática - poeta no enamorado, dama no correspondida, amor simultáneo a varias damas, etc. - que por efectivo desbordamiento del inventario temático. En tal sentido ya advertíamos en nuestras primeras exposiciones de la teoría tipológica, que quizás su mérito más destacado era el de haber establecido el inventario temático de la lírica amorosa clásica como un inventario cerrado y restringido, lo que constituía verdadera sorpresa para las difíciles cábalas establecidas desde la imprevisión impresionista de la crítica tradicional, nutrida en el prejuicio contra toda forma de recurrencia, desde el aliento inconsciente de ambiguas ideas sobre la naturaleza "genial» del creador.

Decimos inventario cerrado y restringido basándonos en el hecho de que ninguno de los innumerables temas secundarios resultantes de nuestros exámenes de dilatadas muestras de sonetos - en la actualidad unos mil quinientos - dejaba de estar a su vez representado en la lista de las terminales de tópicos textuales centrales. Por consiguiente las ochenta terminales de nuestra esquematización de 1978, representaban el inventarió completo de la tópica temática amorosa de la poesía cortés. A ello debe añadirse que los distintos retoques al mencionado esquema introducidos con posterioridad, han subsanado notables imperfecciones $y$ reduplicaciones, aunque en el sentido de adecuar el número total de terminales al inventario real de tópicos sin reiteración. Así pues, las treinta y cuatro terminales del esquema actual (García Berrio, 1981), con la drástica reducción numérica que incorpora, elevan la virtualidad operativa de la propuesta tipológica, al tiempo que restringen aún más - creemos que a sus justos y definitivos términos - la imagen objetiva de topicidad del reducido sistema temático de la lírica clasicista, demostrando -o mejor obligando a formular en términos más exactosel tipo de prejuicios de la ideologia literaria "romántica» a que hacía referencia anteriormente.

3.2. La descripción precedente de los problemas inherentes a la elaboración del sumario de la representación semántica de cada tema, ha sido hecha desde la perspectiva global de la elaboración de una teoría tipológica, y más en concreto centrándola en lo referente a la constitución del contenido temático de las terminales. Sobre la base de tales explicaciones nos resultará ahora más fácil ilustrar con el ejemplo de so- 
netos concretos los procesos de conceptualización en lo que se refiere a la sumarización textual temática.

Como viene siendo habitual en este trabajo, habremos de examinar con mayor pormenor algunos de los textos más problemáticos al respecto. El caso general, de evidencia casi inmediata, no requiere mayor acopio de ilustraciones; lo que no debe inducir al error de proporción de inferir de ello que dicho caso general no represente la mayor frecuencia, como así es, frente al carácter minoritario en la muestra de los casos problemáticos, que hemos seleccionado precisamente en función de su rareza y mayor dificultad ilustrativa.

Quizás la mayor fuente de dificultades para la conceptualización temática la ofrezcan aquellos textos en los que sus distintos componentes temáticos presenten un grado más acusado de afinidad semántica; tal el caso de las terminales tipológicas que son variantes temáticas de las mismas terminales de clase, como «proclamación/ glorificación, galanteo»; «engaño-desengaño» $\left(4_{1} b_{10}\right) /$ «imaginación vs. voluntad» $\left(4_{1}\right.$ $b_{11}$ ) en las quejas de sí mismo con desengaño, etc. En tal sentido, un soneto como el 187 de Fernando de Herrera, "Solo i medroso, del peligro cierto", que reproducimos para facilitar nuestra ilustración, ofrece muy escasos problemas en lo que respecta a la conceptualización de los diferentes temas que lo constituyen:

Solo i medroso, del peligro cierto, qu'en la guerra d'Amor temido avia, con fortuna mejor tarde huia en tanta tempestad seguro al puerto.

Mas enel passo del camino incierto, cuando con mas descuido proseguia, Amor, qu'en vuestros ojos m'atendia; d'un golpe atravesso mi pecho abierto.

I antes, que yo pudiesse de mi pena alabar la ventura, invidiöso huyò con vos, i me dexò perdido;

Cual huye el Parto, do el Eufrates suena, i rebuelve el cavallo pressuroso, dexando al fiero contendor herido. 
La queja de Amor, tema central explícito del soneto - versos 7 y 8 -, aparece con manifiesta separación del conjunto restante de temas: circunstante itinerario (versos 1 y 6 , con la incrustación tópica del tema "tempestad/puerto seguro»), glorificación con superación del sufrimiento (versos 9-10), sufrimiento desesperado (versos 10-11); más el refuerzo final del tema sobre modalidad expresiva de símil (versos 12-14). Como puede verse, la evidente diafanidad en la estructura temática de este soneto, procede precisamente del grado de lejanía de sus temas respecto a su distribución en un esquema tipológico orgánico, ya que ninguno de ellos pertenece al mismo rasgo de clase que los demás. Obviamente podríamos multiplicar el número de estos ejemplos aproblemáticos, los más frecuentes en la muestra, que, como hemos dicho, constituyen la regla; pero tal insistencia no aportaría enseñanza alguna. Preferimos por tanto ilustrar los casos más regulares de dificultad, conscientes, no obstante, de que nos moveremos en el dominio de las excepciones.

Ilustran adecuadamente la condición problemática de las decisiones que comentamos tres sonetos de apariencia inmediata y muy similares, de las Rimas de Lope de Vega. En los tres resuena el tema del confidente, pero, como veremos, con peso específico muy distinto. El soneto 45 incorpora sin duda la temática central del confidente:

Tened piedad de mi, que muero ausente, hermosas ninfas desde blando rio; que bien os lo merece el llanto mío, con que suelo aumentar vuestra corriente.

Saca la coronada y blanca frente, Tormes famoso, a ver mi desvarío; asi jamás te mengüe el seco estio, y esta montaña tu cristal aumente.

Mas qué importa que el llanto mío recibas, si no vas a morir al Tajo, adonde mis penas pueda ver la causa dellas?

Tus ninfas en tus ondas fugitivas y tu cabeza coronada esconde: que basta que me escuchen las estrellas.

El confidente rio - por cierto que excepcionalmente desdoblado en "Tormes» y «ninfas», lo que no añade precisamente acierto al orden 
estructural tópico de esta clase de textos ni a su mérito estéticocumple el requisito estructural temático independiente de constituirse en elemento textual activo, bien que con el mínimo de actividad tópica: "salir a escuchar/esconderse». Pero por lo demás ese mínimo activo, que sirve para darle entrada en el esquema central predicativo-actancial del texto, se ve acrecentado con su condición de soporte de un reiterado tema secundario, el llanto acrecentador del río, símil temático asociado con distintas fórmulas de explicitud variable en los versos 3-4, 7-8, 9-10. El tema límite de la ausencia se ve apenas reflejado en la estructura superficial; sólo en el verso primero, mediante un solo lexema, bien que muy directo, así como en el desarrollo del primer terceto. Sin embargo la reorganización de la estructura profunda textual no presenta la ausencia como tema dominante, ya que ello implicaria una organización invertida consecutiva del tipo:

Tú, Tormes, no vas a desembocar al Tajo > por consiguiente > escóndete, que no correspondería ni siquiera al orden explícito del enunciado; perfectamente recogido, por el contrario, en la organización directa causal de la estructura textual profunda:

$\mathrm{Sal}$ Tormes a escucharme $>$ porque estoy presente $>$ Pero escóndete $>$ porque no desembocas en el Tajo.

Completamente opuesto al caso precedente, pese a la apariencia inmediata de su estructura superficial, sería el del soneto 73 de las mismas Rimas, que transcribimos para su más cómodo cotejo:

Cubran tus aguas, Betis caudaloso, las galeras de Italia, y españolas, de Sevilla a Triana formen solas, por una y otra margen, puente hermoso.

Las naves indias, con metal precioso más hinchadas que de aire sus ventolas, tu pecho opriman libre de las olas del mar, en la Bermuda riguroso.

Apenas des lugar para los barcos, $y$, en el mejor, Lucinda, sin memoria, honre tus fiestas con igual presencia.

Diviértase en tus salvas, triunfos y arcos, mientras que tengo yo por mayor gloria peñas del Tajo, y soledad de ausencia. 
Lo primero a destacar es la condición de simple vocativo del confidente-río, Betis en este texto. Su actividad textual, por consiguiente, es nula, ya que se ha reducido a simple soporte circunstancial, de las "galeras de Italia y españolas» y de las "naves indias», así como escenario de las "diversiones de Lucinda", sin que se registre en todo el texto alusión explicita a la intervención activa del Betis en ninguno de los acaecimientos reseñados. El esquema textual, de encadenamiento lógico explícito escasamente feliz, ofrece el típico contraste de lugares-ríos Betis/Tajo, como marco local de la denotación temática de ausencia. Si bien debe advertirse que la limpieza usual de ese esquema se ve aquí perturbada por dos factores fundamentales: el amplio desarrollo de expansión transformativa del escenario Tajo, que se extiende a las tres primeras estrofas del texto; y en segundo lugar la condición antitópica de la situación contrastada por la ausencia, tristeza y anhelo de romper la separación, que en el texto se traduce en la preferencia gustosa por el escenario y la situación de ausencia. Por lo demás, resulta evidente el desplazamiento del contenido temático central del texto al último terceto, dada la condición de pura expansión transformativa del circunstante escenario en el resto de la composición - con ciertos ecos inusuales del tema de proclamación de la usalida» de la dama a hermosear el paisaje - . En cuyo caso, nos parece absolutamente explícita y aproblemática la fijación del tema de la ausencia en esta composición.

Un tercer texto de Lope todavía (16) de las mismas Rimas establece el límite de problematicidad entre los otros dos. El tema del confidente ac-

(16) Véase el soneto aludido:

Fugitivo cristal, el curso enfrena, en tanto que te cuento mis pesares; pero ¿cómo te digo que te pares, si lloro, y creces por la blanda arena?

Ya de la sierra, que de nieves llena te da principio humilde Manzanares, por dar luz al que tienen tantos mares, mi sol hizo su ocaso en la Morena.

Ya del Betis la orilla verde adorna en otro bosque de árboles desnudos, que en agua dan por fruto, plata en barras.

Yo, triste, en tanto que a tu margen torna, de aquestos olmos, a mis quejas mudos, nidos deshago y desenlazo parras. 
tivo - «enfrena»-, insinuado y restringido retóricamente en el primer terceto, se diluye totalmente en el resto de la composición: por otra parte la contraposición de lugares que establece la temática de ausencia, explícita en las dos estrofas centrales del soneto, queda relativamente contradicha - en especial frente a la explícita presencia del lexema director ausencia en el texto del soneto 73 - con la fórmula expresa del regreso de la dama - la situación típica establecía la desesperación por la imposibilidad de desplazamiento del poeta - ; y mucho más diluida aún por la situación de sufrimiento, la única explícita en el terceto final, que refuerza así con su situación, en virtud de la conocida regla métrica conclusiva, la decisión de catalogar este soneto bajo tal terminal tipológica como tema central.

3.3. Los problemas de conceptualización del tema y con ellos la elaboración del sumario semántico puede crecer en el caso, muy frecuente, de que las diferentes opciones constitutivas presenten mayor afinidad, al estar dominadas por el mismo núcleo terminal de clase temática. Por ejemplo tres textos de canto ofrecerán la ilustración de este tipo de problemas. Empezando por el soneto 179 de las Rimas de Lope de Vega (17) el sumario textual se debate entre las dos modalidades próximas, de proclamación perseverante "para siempre el altar de tu hermosura", y de sublimación, reiterada en la práctica totalidad del texto, pero singularmente en los versos 5-6 y 10-11. En favor de la primera cuentan el tono apasionado de la apelación y la regla métrica; mientras que en apoyo de la segunda es preciso registrar la mayor persistencia y extensión de

(17) Véase el soneto aludido:

Ángel divino, que en humano y tierno velo te goza el mundo, joh!, no consuma el mar del tiempo, ni su blanca espuma cubra tu frente en su nevado invierno;

beldad que del artifice superno imagen pura fuiste en cifra y suma, sujeto de mi lengua y de mi pluma, cuya hermosura me ha de hacer eterno;

centro del alma venturosa mía, en quien el armonía y compostura del mundo superior contemplo y veo.

Alba, Lucinda, cielo, sol, luz, día, para siempre al altar de tu hermosura ofrece su memoria mi deseo. 
las manifestaciones terminales, si bien aún no con la rotundidad esquemática que precisamente este tema de sublimación habia de adquirir en obras posteriores de Lope, justificando exigencias y pretensiones ligadas a circunstancias concretas de su biografía. Adviértase además otros temas, que a nivel textual mucho más secundario se insinúan en el texto, como el retrato implícito, la peripecia de envejecimiento (versos 2-4) y la glorificación por la índole de la dama y de la propia poesia (versos 6-7). Todos ellos, en suma, se recortan dentro de la intuición unitaria central del canto, cuyo sumario textual va desgranando y organizando las notas semánticas de todos estos temas tan vinculados entre sí a través de esa general dependencia temática.

En el soneto 34 de los Versos de Herrera, de contenido muy próximo al anterior (18), la especialización temática del sumario en rasgos de proclamación aparece más netamente afirmada que en el caso anterior. Como en aquél, obran en su favor el tono apelativo - quizás no tan marcado - y la insistencia terminal del tema como regla métrica. Pero sobre todo lo que más contribuye a la nítida rotundidad del tema central es la ausencia o la débil representación de otros temas en competencia. En este texto no se presenta ninguno como el de la sublimación en el soneto anterior; el toque temático de retrato se mantiene como término de ponderación de la hermosura presente, circunscrito al primer cuarteto; en cuanto al de la peripecia de encanecimiento, establece la alternativa de pọnderación correlativa del elemento anterior, cuya conclusión desemboca en el primero de los tercetos, donde se explicita precisamente

(18) He aqui el texto de referencia:

Las hebras d'oro puro, que la frente cercan en ricas bueltas, do el tirano Señor texe los lazos con su mano, i arde'n la dulce luz resplandeciente;

Cuando el ivierno frio se presente, vencedor de las flores d'le]l verano, el purpureo color tornando vano, en plata bolveran su lustre ardiente.

I no por esso Amor mudarà el puesto: que el valor lo assegura $i$ cortesia; el ingenio i del'alma la nobleza.

Es mi cadena i fuego el pecho onesto, i virtud generosa, Lumbre mia; de vuestra eterna, angélica belleza. 
el tema, reinsistido por paráfrasis en el terceto final. Casi los mismos ingredientes textuales reaparecen en el famoso soneto 33 de Algunas obras del mismo Herrera (19), donde el deslinde concreto resulta quizás más extremadamente difícil dentro del sumario temático del canto. El retrato, presente a lo largo de todas las estrofas, aparece invariablemente ponderado mediante el subrayado temático de la glorificación. Así lo corroboran los lexemas "gloria» y uadoro» directrices funtoriales de la predicación desarrollada en los dos primeros cuartetos, y sobre todo la exposición en el terceto final, que viene a corroborar mediante la regla posicional la condicićn de predominio textual del tema, bajo la modalidad concreta de glorificación con superación de la queja.

Para concluir la ejemplificación de este apartado, me referiré todavía a uno de los problemas globales de conceptualización temática más significativos, al punto de haber determinado algunas de las más significativas modificaciones en el curso de la elaboración de esta teoría tipológica. Se trata del tema del galanteo, que fue censado como autónomo dentro del canto, y aun ramificado en dos modalidades $\left(5_{2} a_{1}\right.$, y $\left.5_{2} a_{8}\right)$, en las primeras formulaciones de la teoria (1978), y que en la versión definitiva queda desdoblado en dos modalidades, tanto dentro de la rama de canto $\left(4_{1} a_{3}\right)$ como en la de quejas de la dama $\left(4_{1} b_{2}\right)$. La razón obvia para tal desdoblamiento era el contrasentido de haber incluido, ganados por la identidad estructural del galanteo - vivacidad sintácticosemántica de corte fundamentalmente conceptuoso-, en las únicas terminales de canto existentes en el esquema primitivo, sonetos de con-

(19) Corrobórense nuestras afirmaciones frente al texto aludido:

Ardientes hebras, do s'ilustra el oro, de celestial ambrosia rociädo, tanto mi gloria sois i mi cuidado, cuanto sois del Amor mayor tesoro.

Luzes, qu'al estrellado i alto coro prestais el bello resplandor sagrado, cuanto es Amor por vos mas estimado, tanto umilmente os ónro mas i adoro.

Purpureas rosas, perlas d'Oriënte, marfil terso, i angélica armonia, cuanto os contémplo, tarito en vos m'inflamo;

I cuanta pena l'alma por vos siente, tanto es mayor valor i gloria mia; i tanto os temo, cuanto mas os amo. 
tenido claramente quejoso. $Y$ es que en el caso del galanteo la conceptualización del tema resulta quizás más difícil, porque si en la gran mayoría de las otras terminales la carga insertada en el funtor predicativo, que regula la terminal de la clase temática correspondiente, es mayoritariamente de naturaleza semántica, en este caso nos hallamos en presencia de un contenido temático fuertemente asentado en la base de una modalidad concreta y especial de construcción macrosintáctica. Es decir, se trata de una entidad tipológica muy bien definida, cuyo contenido temático, la especial forma de agudeza conceptuosa, lo llenan recursos semánticos como el equívoco, pero mayoritariamente sintácticosemánticos como la antítesis o el retruécano, alentados por la andadura general de la estructuración macrosintáctica del texto. Casos como éste ponen de relieve la dificultad inherente a los mecanismos de conceptualización y a las estrategias de elaboración del sumario semántico del texto, para determinar sobre él la organización temática del texto.

3.2. La operación de etiquetado supone la asignación de una representación lexémica al fragmento textual sumarizado en el tema, cuya representación semántica incorpora la proposición nuclear deducida. Obviamente, que la etiqueta del tema, ya sea comúnmente una sola unidad léxica, como «retrato», "peripecia», o bien una lexía compleja como "carpe diem» o «imaginación vs. voluntad», no debe ofrecer problemas de conciliación con nuestra definición de la representación semántica sumarizada a través de una fórmula de predicación. Ya es uso sólidamente adquirido en la práctica común de la formalización lógica que cualquier entrada léxica puede ser definida y representada mediante la estructura de predicación (Petöfi, 1973; 243-254; Albaladejo Mayordomo, 1981), no sólo los verbos, sino otros lexemas como substantivos de objeto, adjetivos o preposiciones.

La etiqueta a rótulo temático puede ser, a su vez, deducida, o inducida desde el enunciado textual. El primer caso se da en las no raras ocasiones en que el poeta formula él mismo la quintaesencia de su discurso, con lo que nos ofrece el tema, como en el caso del soneto antes mencionado de Quevedo, incluso bajo la ficción de una forma tan inmediatamente sintético-temática, como la del epitafio: "Ya fue gloria de Amor hacerme guerra»; caso éste ni mucho menos infrecuente en nuestra muestra habitual de sonetos amorosos. Obviamente los titulos de los textos, bien sean propuestos por el propio poeta, o bien por lectores y editores contemporáneos con evidente intención de "enarratio» de un sentido del mensaje que preveían iba a ser cada vez más opaco con el paso del tiempo, presuponen e ilustran excelentes ejercicios de «conceptualización» del tema. En tal sentido, por ejemplo, nos propo- 
nemos abordar en un trabajo futuro los títulos de los primeros editores de Quevedo, en los que por lo general tanto la deducción de la representación semántica como el etiquetado léxico son perfectos y han ayudado indeciblemente a la adecuada comprensión de las intenciones de Quevedo; pensemos por ejemplo en las excelencias del título "Amor constante más allá de la muerte». Sin embargo lo más común es que en nuestro trabajo de etiquetado - sin duda uno de los más difíciles y costosos en todo ejercicio tipológico - los casos de lexías deducidas, como las hasta ahora indicadas, no sean los más frecuentes. La deducción del rótulo léxico se verifica por lo común en el nivel del lexema-tecnicismo; así, fórmulas léxicas de apariencias más o menos caprichosas incorporadas a nuestro esquema tipológico, como canto, queja o sufrimiento, responden a las denominaciones más usuales en los textos tipologizados para los contenidos semánticos significados por ellas. Se trata, bien es cierto, de lexemas muy usuales y comunes del español, del de entonces como del actual; pero en su condición de tales los hemos asumido. Así, por ejemplo, el tampoco raro término de retrato $\left(4_{1} a_{4}\right)$ nos ha sido sugerido desde la conceptualización usual en la época de las descripciones de las hermosuras físicas de la dama; recuérdense títulos como "Retrato no vulgar de Lisi», u otros equivalentes. En ocasiones, términos como "enfermedad" $\left(4 c_{1}\right)$, con el que hemos etiquetado el proceso de sufrimiento amoroso sin mención explícita de su límite en la "muerte» $\left(4 c_{2}\right)$, si bien pueden parecer sustitutos puramente metafóricos del tecnicismo temático correspondiente - bien sea por ignorancia nuestra o bien por inexistencia del mismo-, se descubren en la lectura de los textos correspondientes como genuinos tecnicismos y fórmulas metafóricas habituales en el intercambio comunicativo tópico de la época en el dominio del amor cortés.

La posibilidad de deducir directamente del texto el lexema-rótulo temático ha de ser siempre preferida a cualquier otra opción de elaboración personal del analista. Términos temáticos como «engaño/ desengaño», «imaginación», o mejor "fantasía»/«voluntad» $\left(4, b_{11}\right)$ en el engaño a sí mismo, tienen la enorme ventaja para las operaciones tipológicas de orientar ya desde el rótulo temático a la estructura nuclear del tema en el texto, en cuya composición los elementos mencionados desempeñan el papel básico que determinó la necesidad de acuñarlos como tecnicismo en el léxico contemporáneo de la clase temática. Pero no siempre la complejidad de la representación semántica incorporada a una sola clase temática permite tales asunciones léxicas; pensemos en casos como el que hemos rotulado de "peripecia». Según es notorio, la «peripecia» $\left(4_{1} a_{6}\right)$ como denominación de aconte- 
cimiento o "accidente imprevisto que cambia el estado de las cosas", no se había generalizado en el léxico contemporáneo a los textos de la muestra desde su concreta acepción de barbarismo procedente del léxico de la poética trágica griega; o al menos no se había generalizado en términos comparables a su difusión popular moderna, en la cual incluso queda bastante desdibujado su valor primitivo de tecnicismo dramático. En consecuencia, ninguno de los textos etiquetados por nosotros como de "peripecia» incluye este lexema en el inventario léxico de su texto. Por otra parte, la variedad de situaciones iniciales: accidentes, gesto, adorno, etc. que constituyen el arranque intrascendente del pretexto para el canto, clave semántica de este tema, sólo puede ser cubierta con cierta adecuación mediante un lexema de contenido significativo lo suficientemente amplio, como lo es «peripecia», para incluir algún sema o significado mínimo común comportado por la totalidad de las situaciones iniciales.

El caso mencionado de la etiqueta léxica "peripecia» supone ya una muestra de la modalidad de la rotulación inductiva que señalábamos antes, como alternativa de las deducidas de elementos léxicos presentes en la manifestación lineal terminal del texto. Las distintas modalidades de inducción en este caso obedecen a causas muy diferentes. Ya hemos aducido las que explican el caso de "peripecia», más bien vinculados al grado de relativa dispersión significativa de los enunciados textuales constitutivos de la clase tipológica-temática; ejemplo análogo «a fortiori» sería la misma denominación de "vario» $\left(4_{1} d_{3}\right)$ para la modalidad de "confidente inanimado no río" o en menor grado las de "escenario" $\left(4_{1} e_{4}\right)$ e «itinerario» $\left(4_{1} e_{5}\right)$ para significar el contenido temático de ciertos textos con hipertrofia descriptiva del circunstante de lugar, directa $o$ metafórica. Alternando con la anterior, otro grupo de etiquetas inductivas obedece más bien a la interposición interpretativa-metateórica de la actividad del analista, casos como «glorificación» $\left(4_{1} a_{2}\right)$, «sublimación» $\left(4_{1} a_{5}\right)$ o "galanteo» son muestras inequivocas del análisis impuesto por parte del constructor de la tipologia a una situación objetiva textualmente no explícita, salvo algunos sonetos excepcionales de "glorificación»:

La interpretación metalingüistica interpuesta creadora de rótulos por inducción cuenta con una variante de funcionamiento muy análogo en las etiquetas debidas a la interposición interpretativa metalingüistica. En tales casos no se trata, como en la modalidad anterior, de la incidencia de la interpretación de un texto de presupuestos no inmanentes de ámbito pluritextual, cuya vinculación es relativa al conocimiento de la teoría general que se sigue del establecimiento de la tipología concreta. Se trata en estos ejemplos de estrictos rótulos de la metalengua y no de 
la metateoría, como serían los de etiquetas tales como "símil temático» $\left(4_{1} b_{2}, 4_{1} c_{3}, 4_{1} c_{6}\right)$, «antítesis» para la definición de Amor $\left(4_{1} b_{9}\right)$, "puntual-instantáneo» $\left(4_{1} e_{1}\right)$ y «durativo-proceso» $\left(4_{1} e_{2}\right)$ para la del circunstante temporal, etc. La razón última de estos rótulos debe ser justificada en términos de "grado de dispersión significativa de los enunciados textuales». Lo que explica además que en casos como éstos se eviten como rótulos temáticos principales los lexemas-testigo clave del texto, tales como «llanto/río», «luz/sombra», «hielo/fuego» etc.; ya que la tematización primordial específica de tales tópicos, que tendría además la ventaja de rambiar la modalidad de rotulación de inductiva en deductiva, lesionaría el principio de economía del sistema, esencial para el establecimiento tipológico, al tiempo que contribuiría a desdibujar las semejanzas temáticas de procedimiento funcional, que otorgan legitimidad genérica e interés superiores a este tipo de establecimiento tipológico sobre el atomismo de especificidades incompatibles con el ideal de economía tipológica; aun sacrificando el criterio de preferencia deductivo-inductivo para la etiquetación.

De la misma manera que al ocuparnos de los problemas de localización textual del tema indicábamos la incidencia apriorística de la experiencia histórico-literaria, podemos invocar ahora dicho componente de explicación para justificar la mayor parte de las decisiones de conceptualización, sumarización y, en último término, de etiquetado. Más bien creo que habría que insistir en la condición de simultaneidad con que en la práctica de las estrategias de tipologización acontece la génesis de todas las decisiones anteriores, precisamente desde la perspectiva creada por la referida experiencia histórico-literaria. Es en último término la gravitación de dicho sistema de presuposiciones culturales lo que posibilita la práctica de la actividad tipológica, descubriendo en unos casos la funcionalidad de las categorías-grupo bien conceptualizadas en la historia literaria tradicional -como en nuestro caso las de "celos» $\left(4_{1} b_{7}\right)$, "carpe diem» $\left(4_{1} b_{5}\right)$, o «in morte» $\left(4 c_{2}\right)$ y recomponiendo en otros las categorías-grupo que contribuyen a fijar la funcionalidad de las primeras, bien conocidas, dentro de la organicidad no arbitraria que exige la lógica de todo sistema tópico, como sin duda lo era el de nuestra lírica clásica. En tales condiciones podemos decir que la operación tipológica no puede contradecir la experiencia derivada de los presupuestos histórico-literarios, pero debe organizarla.

Llegados a este punto es posible que en nuestra última afirmación hayamos suscitado - y aun facilitado - objeciones a la validez y necesidad del trabajo tipológico en sistemas culturales, que venimos defendiendo y justificando en los últimos tiempos en trabajos como éste. Pe- 
ro advertimos entre paréntesis que, en ciencia, sólo cuando se ha alcanzado y experimentado la íntima convicción de la verdad y el valor explicativo de los propios descubrimientos - dentro de la humildad inolvidable de toda actividad humana: científica, humanística, y sobre todo filológica, por este orden-, se cede a la debilidad de constituirse públicamente en "abogado del diablo» contra las propias ideas; quizás sea porque desde la seguridad a que aludía, se aprecia infinitamente en más to poco que cualquier cosa propia sea capaz de sugerir al raro lector de buena fe, que los muchos peligros de tergiversación que pueda ofrecer la misma afirmación en manos de los abundantes curiosos de mala. De todos modos creo que, mirada con el detenimiento y la perspectiva requeridos, la conclusión de que antes partíamos no se revela, ni mucho menos, como negativa, ni aun mínimamente deprimidora para la dimensión tipológica de la teoría general científica.

Organizar un "corpus» suficientemente complejo de datos culturales viene a equivaler en la dinámica de la historia de las ciencias, al menos en las humanísticas, a descubrir la fisonomía de un sistema cultural. Porque los datos culturales existen conglomerados, por ejemplo existen ediciones de todos los autores que he elegido como muestra $y$ aun de muchos otros con los que la podría ampliar, pero usualmente no están funcionalmente explicados. Para la parcela tipológica de la teoría de la ciencia, toda explicación funcional postula indefectiblemente la adecuación relevante del "corpus». Así, por ejemplo la estilistica tradicional, que consagró el principio del inmanentismo analítico, intentó explicaciones limitadamente funcionales, en el mejor de los supuestos, para ciertos fenómenos aislados de algunos poemas, pero obviamente le faltó en todos los casos la relevancia del corpus. Sólo quizás algún post-formalista como Propp, o folkloristas estructurales más modernos como Pierre Maranda han operado dentro de presupuestos inmanentistas con "corpora» que satisfacen las exigencias de relevancia tipológica.

Organizar por tanto un "corpus» complejo como el nuestro, que es lo único representativo, supone el enriquecimiento del dato aislado, esclarecido sólo en los restringidos límites que le crean los análisis inmanentistas, a través de su delimitación funcional en el seno del organismo cultural en que ha vivido. No otro ha sido en lingüistica el tipo de servicios de la fonologia, a la fonética descriptiva e histórica; sólo que en lo que concierne a sistemas culturales como el que nos ocupa, se trata de la constatación sistemática de un conjunto de datos aislados infinitamente más numeroso, complejo y heterogéneo que el de los que precisa constatar la fonología para definir un sistema dado como estado de lengua, diferente del anterior $y$ del sucesivo. El tipo de intuiciones 
histórico-literarias inorgánicas que constituyen el presupuesto operativo de las operaciones tipológicas, se presenta tan extraordinariamente fragmentado, incompleto, y privado de toda aproximación de márgenes proporcionales, que resulta absolutamente desproporcionado el servicio que su toma en consideración presta a la tipología, frente a los beneficios de esclarecimiento que ésta le brinda a aquéllas. De ahí que nuestra indicación de que la tipología «no puede contradecir los presupuestos aportados por la historia literaria», se refiere a éstos no como una pauta estable que haya simplemente de corroborar; sino más bien como un conjunto de vestigios, de cimientos o hitos en una suerte de paraje desolado, cuya presencia será directriz y coactiva - más en el sentido de delimitar descarrios hipotéticos que en el construir hipótesis - en la edificación del gigantesco edificio lógico de las tipologías culturales.

\section{REFERENCIAS}

Agricola, Erhard (1976), "Vom Text zum Thema», en: Daneš, František/Viehweger, Dieter (Hrsg:) (1976), pp. 13-27.

Albaladejo Mayordomo, T. (1981), «Aspectos del análisis formal de textos» en Revista Española de Lingüistica, 1981, 11, 1, pp. 117-160.

Dahl, Östen (ed.) (1974), Topic and Comment, Contextual Boundness and Focus, Papiere zur Textlinguistik, 6, Hamburgo, Buske.

Bánréti Zoltán (1982), "The topic of text and the interpretation of texts», en J.S. Petöfi (ed.), Text vs. Sentence Continued. Papiere zur.Textlinguistik, 29, Hamburgo, Buske, 1982, pp. 43-57.

Daneš, František (1970), "Zur linguistischen Analyse der Textstruktur», en Folia Linguistica, 4, pp. 72-79.

- (ed) (1975), Pepers on functional sentence perspective, Praga.

- (1976), «Zur semantischen und thematischen Struktur des Kommunikats», en: Daneš, František/Viehweger, Dieter (Hrsg.) (1976), Probleme der Textgramma ijk, Studia Grammatica, XI, Berlin, Akademie Verlag. pp. 29-40.

Dijk, Teun A. van (1972), Some Aspects of Text Grammars. La Haya, Mouton. 
-(1977), Text and Context, Londres, Longman (Versión española: Texto y contexto, Madrid, Cátedra, 1980).

-(ed.) (1980), Story Comprehension, Poetics, 9, 1-3 (Special issue), 1980.

- (1980), "Story Comprehension: An Introduction», en: Dijk, Teun A. Van (ed.) (1980), pp. 1-21.

- Kintsch, Walter (1978), "Cognitive Psychology and discourse: Recalling and Summarizing Stories», en: Dressler Wolfgang U. (ed.) (1978), Current Trends in Textlinguistics, Berlin-Nueva York, De Gruyter, pp. 61-80.

Filmore, Charles J. (1968), "The Case for Case», en: Bach, Emmon/Harms, Robert T. (eds.) (1968), Universa/s in Linguistic Theory, Nueva York, Holt, Rinehart and Winston, pp. 1-88.

- (1971), "Hacia una teoria moderna de los casos», en: Contreras, Heles (ed.) (1971), Los fundamentos de la gramática transformacional, Méjico, Siglo XXI, pp. 45-65. (Versión original, 1966).

- (1977), "The Case for Case Reopened", en: Heger, Klaus/Petöfi, János S. (Hrsg.) (1977), Kasustheorie, Klassifikation, semantische Interpretation, Papiere zur Textlinguistik, 11, Hamburgo, Buske, pp. 3-26.

García Berrio, A. (1970), Bosquejo para una teoría de la frase compuesta en español, Murcia, Universidad.

- (1973), Significado actual del Formalismo ruso, Barcelona, Planeta.

-(1975), Introducción a la poética clasicista, Barcelona, Planeta.

- (1977), «Text Linguistics and the Lyric Text», publicado en Forastieri. -y otros (ed.), (1980), On text and context, Puerto Rico, Ed. Universitaria, pp. 95-138.

- (1977), Formación de la Teorla Literaria moderna, Madrid, CUPSA, Vol. I.

-(1978), "Lingüística del texto y texto lírico», en Revista Española de Lingülstica, 8, 1, pp. 19-75.

-(1978 a), "Tipología textual de los sonetos clásicos españoles sobre el carpe diem», en Dispositio, III, 9, pp. 243-293.

- (1979), "A Text-Typology of the Classical Sonnets», en Poetics, 8, pp. 435-458.

- (1980), «Estatuto del personaje en el soneto amoroso del Siglo de Oro», en Lexis, 6, 1 pp. 71-75.

- (1980 a), "Una tipologia testuale di sonetti amorosi nella tradizione classica spagnolà), en Lingua e Stile, XV, 3, pp. 451-478.

- (1980 b), "Construcción textual en los sonetos de Lope de Vega. Tipología del macrocomponente sintácticon, en Revista de Filología Española, LX, (1978-1980), pp. 23157.

- (1980 c), Lingüística, literalidad/poeticidad (Gramática, Pragmática, Texto), en 1616. Anuario de la Sociedad Española de Lit. general y comparada, pp. 125-170.

- (1980 d), Formación de la Teoria Literaria moderna, Murcia, Universidad, Vol. II.

- (1981), «Macrocomponente textual y sistemático tipológico» en Zeitschrift für Romanische Philologie, 97, 1/2, pp. 146-171.

- (1982), "Definición macroestructural de la lírica amorosa de Quevedo (un estudio de "forma interior" en los sonetos)", en Homenaje a Quevedo. Actas de la ll Academia Literaria Renacentista, Salamanca, 1982, pp. 261-293.

Greimas, Algirdas J. (1970), Du sens, Paris, Seuil, (Versión española: En torno al sentido, Madrid, Fragua, 1973).

- (1971), Semántica estructural, Madrid, Gredos. (Versión original, 1966).

- (1976), Maupassant. La sémiotique du texte: exercices pratiques, París, Seuil.

Halliday, Michael K. / Hasan Ruqaiya (1976), Cohesion in English, Londres, Longman. Heger, Klaus (1976), Monem, Wort, Satz und Text, 2. erweiterte Auflage, Tübingen, Niemeyer.

-(1977), "Aktantenfunktionen und abstrakte Kasus», en: Heger, Klaus/Petöfi, János 
S. (Hrsg.) (1977), Kasustheorie, Klassifikation, semantische Interpretation, Papiere zur Textlinguistik, 11, Hamburgo, Buske, pp. 43-69.

Heydrich, Wolfgang (1977), "Zur Einführung von Argument-labels», en: Petöfi, János S./Bredemeier, Jürgen (Hrsg.) (1977), Das Lexikon in der Grammatik. Die Grammatik im Lexikon, Papiere zur Textlinguistik, 13, 2 vols., Hamburgo, Buske, vol. II, pp. 439-492. -(1978), "Das System der Argumentrollenindikatoren im Uberblick», en: Biasci, Claudia/Fritsche, Johannes (Hrsg.) (1978), Texttheorie-Textrepräsentation, Papiere zur Textlinguistik, 18, Hamburgo, Buske, pp. 103-114.

. Hirsch, Eric D. (1973), Teoria dell'interpretazione e critica letteraria, Bolonia, II Mulino. Lehrberger, John (1974). Functor Ana/ysis of Natural Languages, La Haya, Mouton. Li, Charles N. (1976), Subject and Topic.

Longacre, Robert E. (1964), Grammar Discovery Procedures, La Haya, Mouton.

- (1965), "Some Fundamental Insights of Tagmemics», en: Language, 41, 1, 1965, pp. 65-76.

-(1970), "Hierarchy in Language», en: Garvin, Paul L. (ed.) (1970), Method and Theo$r y$ in Linguistics, La Haya, Mouton, pp. 173-190.

- (1976), An Anatomy of Speech Notions, Lisse, De Ridder.

Petöfi, János S. (1973), "Towards an Empirically Motivated Grammatical Theory of Verbal Texts», en: Petöfi, János S./Rieser, Hannes (eds.) (1973), Studies in Text Grammar), Dordrecht, Reidel, pp. 205-275.

- (1975), "'Modalité' et 'topic-comment' dans une grammaire textuelle à base logique», en: Petöfi, János S. (1975), Vers une théorie partielle du texte, Papiere zur Textlinguistik, 9, Hamburgo, Buske, pp. 35-80.

Petöfi, János S./García Berrio, Antonio (1979), Lingüistica del texto y Crítica literaria, Madrid, Comunicación.

Ramón Trives, Estanislao (1979), Aspectos de semántica lingü/stico-textual, Madrid, Istmo-Alcalá.

Rojo, Guillermo (1978), Cláusulas y oraciones, Santiago de Compostela, Universidad. Sgall, P. (1973), «Focus and contextual boundness», en: Dähl, O. led.), 1976.

Tesnière, Lucien (1969), Eléments de syntaxe structurale, Paris, Klincksieck.

Todorov, Tzvetan (1968), Théorie de la Littérature, París, Seuil.

- (1968 b), Grammaire du Decamerón, París, Seuil. IVersión española: Gramática del Decamerón, Madrid, Taller de Ediciones J.B., 1973).

Vera Luján, Agustín (1977), Análisis semiológico de "Muertes de perro", Madrid, CUPSA.

Weinrich, Harald (1981), "Comunicantes y actantes", en: Weinrich, Harald (1981), Lenguaje en textos, Madrid, Gredos, pp. 51-74. (Versión original, 1976). 